\title{
A Review on Aerosol-Based Direct-Write and Its Applications for Microelectronics
}

\author{
Justin M. Hoey, ${ }^{1}$ Artur Lutfurakhmanov, ${ }^{1}$ Douglas L. Schulz, ${ }^{1}$ and Iskander S. Akhatov ${ }^{1,2}$ \\ ${ }^{1}$ Department of Mechanical Engineering, Center for Nanoscale Science and Engineering, North Dakota State University, \\ Fargo, ND 58105, USA \\ ${ }^{2}$ Center for Micro and Nanoscale Dynamics of Dispersed Systems, Bashkir State University, Ufa 450076, Russia
}

Correspondence should be addressed to Justin M. Hoey, justin.hoey@ndsu.edu

Received 25 December 2011; Accepted 4 June 2012

Academic Editor: Kyoung Moon

Copyright (C 2012 Justin M. Hoey et al. This is an open access article distributed under the Creative Commons Attribution License, which permits unrestricted use, distribution, and reproduction in any medium, provided the original work is properly cited.

\begin{abstract}
Aerosol-based direct-write refers to the additive process of printing CAD/CAM features from an apparatus which creates a liquid or solid aerosol beam. Direct-write technologies are poised to become useful tools in the microelectronics industry for rapid prototyping of components such as interconnects, sensors, and thin film transistors (TFTs), with new applications for aerosol direct-write being rapidly conceived. This paper aims to review direct-write technologies, with an emphasis on aerosol-based systems. The different currently available state-of-the-art systems such as Aerosol Jet CAB-DW, MCS, and aerodynamic lenses are described. A review and analysis of the physics behind the fluid-particle interactions including Stokes and Saffman force, experimental observations, and how a full understanding of theory and experiments can lead to new technology are presented. Finally, the applications of aerosol direct-write for microelectronics are discussed.
\end{abstract}

\section{Introduction}

Direct-write printing is an additive technology used to controllably deposit features onto samples in patterns defined by computer-aided design/computer-aided manufacturing (CAD/CAM) software allowing rapid prototyping of various geometries without the use of lithography $[1,2]$. In 2008, Hon et al. [2] reviewed this field and categorized directwrite into four main categories. The first category is "flowbased direct write" where technologies such as nScript and MicroPen employ a microdispensing system with a needle or orifice to continuously deposit features as small as $25 \mu \mathrm{m}$ at speeds up to $300 \mathrm{~mm} / \mathrm{s}$. Flow rates in the $\mathrm{nL} / \mathrm{s}$ range are typical, and flow-based direct write is capable of printing materials with a viscosity from 0.5 to $10^{6} \mathrm{cP}$ which allows deposition of a variety of ink compositions.

The second category is "energy beam based direct write" and includes several technologies that use high-power lasers to transform and/or propel material onto a substrate. The laser-based systems include laser-enhanced electroless plating (LEEP), matrix-assisted pulsed laser evaporation directwrite (MAPLE-DW), laser-engineered net shaping (LENS)
[3], laser-guided direct-write (LGDW) [4], and Mesoscribe Technologies [5]. While the details for all of these approaches are beyond the scope of this paper, as an example, we briefly describe MAPLE-DW which is a process that uses a pulsed UV laser to forward transfer a thin film of material from a transparent "ribbon" to a substrate. Interaction of the laser with the solvent component of the "ribbon" causes rapid evaporation whereby the irradiated portion is ejected from the ribbon and transported $\sim 100 \mu \mathrm{m}$ where it is deposited onto the substrate [1]. The areal dimension of the deposit is similar in size to laser area with a common diameter around $30 \mu \mathrm{m}$ [6]. Film thicknesses from 1 to $20 \mu \mathrm{m}$ are commonly observed when ribbons $\sim 25 \mu \mathrm{m}$ are employed [1]. This process requires specialized inks that have appropriate viscosity and UV absorption. Minimum resolution of the as-deposited lines is limited by the laser spot size but printed features with line widths down to $2 \mu \mathrm{m}$ can be realized by lasertrimming the patterns [6]. Included in this category are also non laser-based approaches such as focused ion beam (FIB) direct-write. This method uses gallium ion bombardment with precursor gases to deposit features as small as $80 \mathrm{~nm}$ at volumetric print rates of $0.05 \mu \mathrm{m}^{3} / \mathrm{s}$ [2]. 
"Tip-based direct write" is the third category and includes dip pen nanolithography (DPN), nanofountain pen (NFP), and capillary-based liquid microdroplet deposition [7]. DPN utilizes an atomic force microscope (AFM) tip to deposit films onto a substrate. After the AFM probe is dipped in a liquid, the tip is brought into contact with the substrate where the liquid flows onto the substrate as the AFM moves in a desired pattern with nanoscale resolution. NFP is a variation of DPN where liquid is dispensed through a hollow tip which is in contact with the substrate. This method has been scaled to multiple tips (up to 12) while stilling maintaining sub-100 nm resolution. Capillary-based liquid microdroplet deposition was recently developed where the application of pressure into a capillary causes a liquid meniscus to form at the outlet [7]. Touching the substrate with the liquid meniscus (not the capillary) and subsequent capillary retraction give liquid deposition on the substrate where the size of the deposit may be as small as $10 \%$ of the capillary inner diameter with dimensions as small as $32 \mu \mathrm{m}$ observed for a $300 \mu \mathrm{m}$ capillary. Substitution of a nanocapillary for the microcapillary in this approach should allow nanodroplet features that maintain a resolution similar to that already demonstrated by DPN and NFP.

The fourth category is termed "droplet-based direct write." Perhaps the most widely investigated droplet-based DW method is inkjet where thermal, piezoelectric, hydrodynamic, electrostatic, and acoustic energies produce small droplets of liquid that are ejected from a nozzle. Both continuous inkjet (CIJ) and drop-on-demand (DOD) versions are available. Resolution down to $<20 \mu \mathrm{m}$ has been realized with inkjet, and the noncontact approach is scalable (hundreds to thousands of nozzles in a single head) for high-throughput operations. Ink-jet is very sensitive to the characteristics of the printing ink because only a limited viscosity range is atomizable, and nozzles can become easily clogged if the ink is too volatile, but certain volatility is required for correct drying once the ink is deposited. The nozzle-to-substrate distance must be precisely controlled which complicated printing over nonplanar substrates [2].

Aerosol-based direct-write (A-DW) is a subset of droplet-based direct-write. Two such methods that employ liquid feed are Aerosol Jet and CAB-DW (collimated aerosol beam direct write) and were developed by Optomec and North Dakota State University (NDSU), respectively [8, 9]. Aerosol Jet and CAB-DW use a focused aerosol spray to deposit material with sub- $10 \mu \mathrm{m}$ resolution. An aerosol may be defined as a suspension of fine liquid or solid particles in a gas. One method that employs a solid feed is microcold spray (MCS) where ductile metal particles of material are accelerated to near or above sonic velocities through a focusing nozzle and deposited onto a substrate $[10,11]$. MCS is similar to Aerosol Jet and CAB-DW but the deposited lines exhibit conductivities near the bulk value without a postdeposition thermal treatment. The previous techniques worked well for mesoscopic particles but are not designed for nanoparticles. A focusing technique developed by researchers at the University of Minnesota uses a set of aerodynamic lenses under vacuum conditions to focus nanocrystal agglomerates and deposit them on a substrate
[12-15]. Examples of this technique for direct-write applications such as for microelectromechanical systems (MEMS) are minimal, but depositions of traces as small as $35 \mu \mathrm{m}$ wide were reported.

The intent of this paper is to provide a comprehensive current review of A-DW methods which includes discussions on the different systems as well as the aerosol flow physics. This paper is arranged into the following sections: (1) a discussion of the various A-DW systems; (2) a review of the aerosol physics relating to aerosol focusing and experimental validation; (3) a review of the applications where A-DW is being used to print components of electronic devices.

\section{Aerosol Direct-Write Systems}

2.1. Aerosol Jet-Single Nozzle with Liquid Aerosol. Aerosol direct-write is a process where an aerosol beam is concentrated and directed toward a substrate to produce desired surface features (e.g., dots or lines) without using masks or postpatterning (i.e., laser trimming). Aerosol spray has been used for decades by the paint industry for thin and thick coatings. The ability to focus the aerosol spray to small $(<100 \mu \mathrm{m})$ dimensions gives beams of material and substantiates the term direct-write. The first A-DW method to be introduced to the community was Aerosol Jet. Aerosol Jet was formerly referred to as $\mathrm{M}^{3} \mathrm{D}$ (maskless mesoscale materials deposition) and was developed by Optomec [16] under the Defense Advanced Research Projects Agency (DARPA) Mesoscopic Integrated Conformal Electronics (MICE) program. The commercially available system is designed to print traces from $10 \mu \mathrm{m}$ to $5 \mathrm{~mm}$ in width at translation speeds up to $200 \mathrm{~mm} / \mathrm{s}$. Liquid inks viscosities between 0.5 and $2500 \mathrm{cP}$ are typically employed. The deposition of materials using Aerosol Jet is illustrated in Figure 1.

The deposition process begins with atomization of a precursor liquid ink into 1 to $5 \mu \mathrm{m}$ diameter droplets with either an ultrasonic (commonly 1.6-2.4 MHz) or pneumatic atomizer. These droplets are then entrained in a carrier gas and transported to a deposition head where an annular flow of sheath gas is added. The sheath gas indirectly acts as a focusing mechanism by occupying the outer portion of the flow tube. This causes the aerosol to be limited to the center of the flow in a manner that is proportional to the volume of the sheath gas. If a pneumatic atomizer is used, a virtual impactor is placed immediately before the deposition head. This device concentrates the aerosol by removing excess gas flow and decreases the polydispersity of the aerosol by removing very small $(<1 \mu \mathrm{m})$ particles. After the deposition head, the aerosol is further focused inside a converging nozzle about $2 \mathrm{~cm}$ long with an exit diameter between 50 and $300 \mu \mathrm{m}$. The delivery process is continuous in that the aerosol and gas flow is not cycled on/off when deposition requires termination (e.g., at the end of a line). Rather, a shutter arm blocks the aerosol flow while the substrate is translated to the next prescribed location as per the CAD/CAM program. The aerosol exits the nozzle at a velocity of 10 to $100 \mathrm{~m} / \mathrm{s}$ and impacts a sample while maintaining a nozzle-to-substrate (stand-off) distance of 1 to $5 \mathrm{~mm}$. This large range of standoff distance simplifies printing over irregular substrates or 


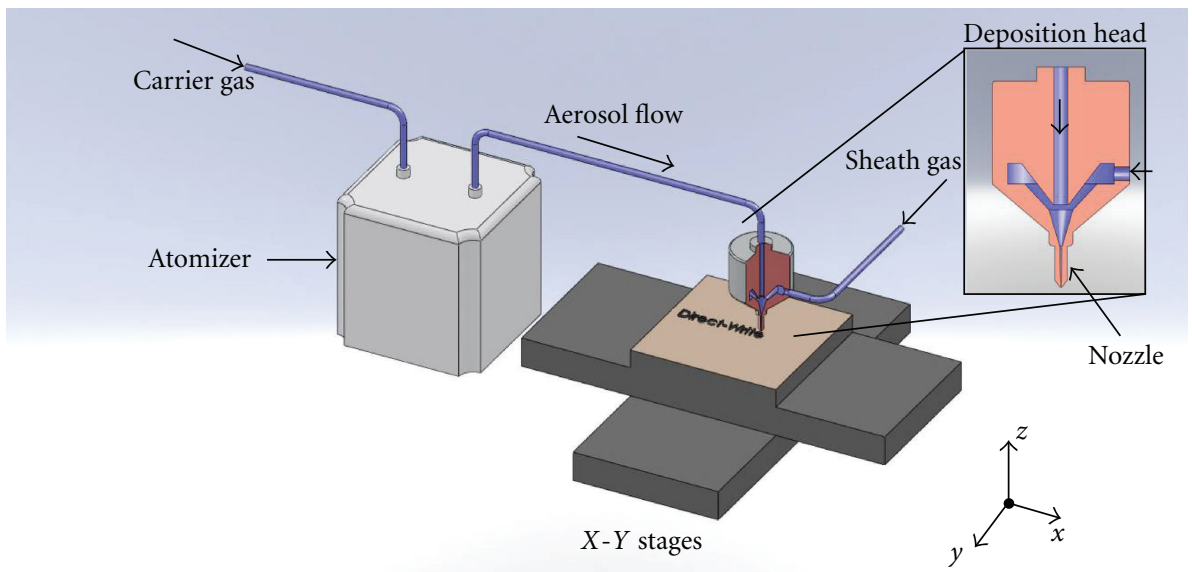

Figure 1: Diagram of Aerosol Jet system.

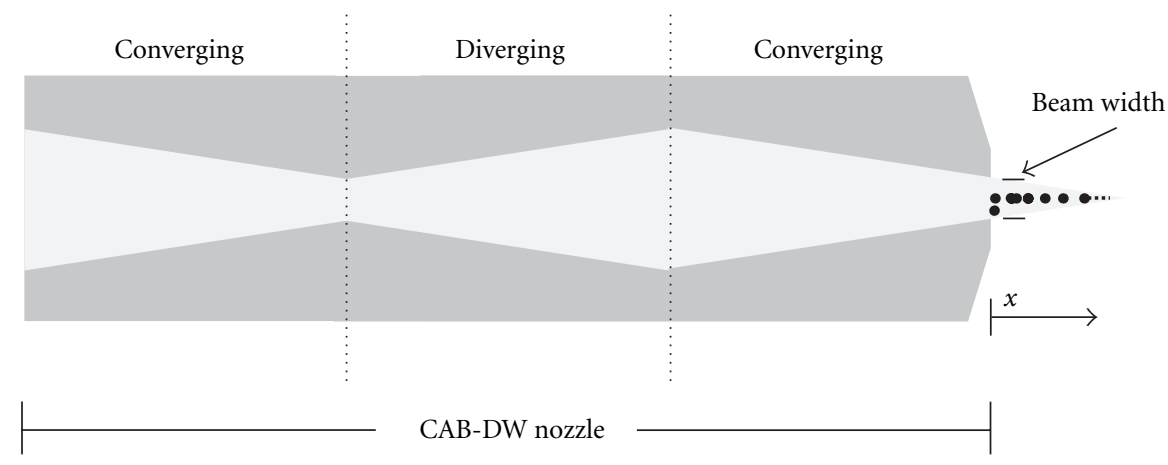

FIGURE 2: Illustration of 3-component converging-diverging-converging CAB-DW nozzle and measurement of aerosol beam width.

other device components such as interlayer dielectrics. A 40-nozzle Aerosol Jet system is now available for parallel processing where the top metallization layer on $15 \times 15 \mathrm{~cm}^{2}$ solar cells can be printed in less than three seconds [2]. Aerosol Jet is capable of producing high quality features but yet requires some effort to remove excess overspray and to preclude nozzle clogging.

2.2. CAB-DW: Multiple Nozzle with Liquid Aerosol. CABDW is a technology developed at NDSU $[9,17]$ which consists of a three-component converging-diverging-converging nozzle (Figure 2) capable of reducing depositions from the Aerosol Jet system to $5 \mu \mathrm{m}$ by further collimating and focusing the aerosol beam. Other characteristics of CABDW are nearly identical to that of Aerosol Jet. The ability to develop an improved nozzle design was only realized after an extensive experimental-analytical analysis was performed on the Aerosol Jet system. Aerosol particles entrained in the nozzle were modeled using a Lagrangian tracking scheme in Poiseuille flow through a linearly converging nozzle using Stokes and Saffman forces of fluid-particle interaction. The trajectories of individual particles were calculated, and the aerosol beam width exiting the nozzle was determined after summing the trajectories of several particles exiting the nozzle.
The aerosol beam width was experimentally determined by measuring the intensity of scattered laser light from the aerosol beam emanating from the nozzle using a CCD camera and microscope. The theoretical beam width (measured at full-width half-max, FWHM) was then compared to experiment, with both theory and experiment similar after adjustment of predicted particle size and corrections to the forces of interaction. After the analytical model was developed, new nozzle geometries were input to the model, with corresponding beam widths calculated. The 3-component nozzle appeared to have a much better collimation and focus theoretically and was chosen for experimental verification. The beam width from the CAB-DW nozzle was measured and compared to the single nozzle (Aerosol Jet, conventional aerosol spray) as illustrated in Figure 3. In this case the CAB-DW nozzle provided for a much more collimated and focused beam with a minimum beam width of $1.9 \mu \mathrm{m}$ at $2 \mathrm{~mm}$ past the nozzle exit as compared to $5.0 \mu \mathrm{m}$ at $1.8 \mathrm{~mm}$ past the nozzle exit for the conventional aerosol spray (Aerosol Jet) [18].

Not only was the aerosol beam more focused with CABDW than Aerosol Jet, but the printed lines were also thinner when comparing the two at identical conditions $(25 \mathrm{sccm}$ carrier gas, $15 \mathrm{sccm}$ sheath gas, $2 \mathrm{~mm}$ stand-off height, $30 \mathrm{~mm} / \mathrm{s}$ translation) where aerosol Jet afforded $31 \mu \mathrm{m}$ wide 


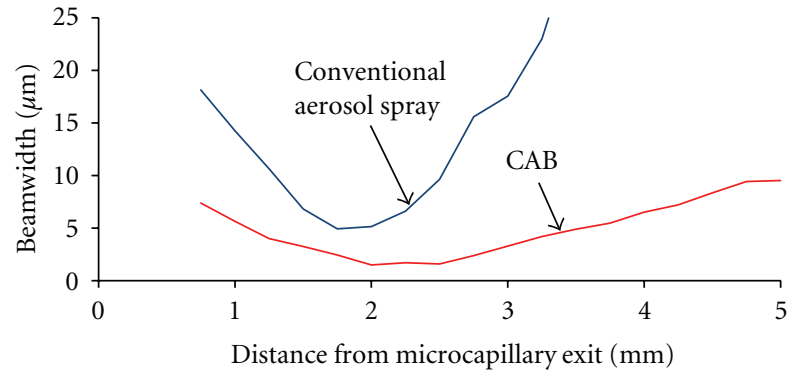

FIGURE 3: Graph of experimental aerosol beam width versus distance from the nozzle exit for (1) Aerosol Jet (conventional aerosol spray) and (2) CAB-DW, from Schulz et al. [18], Copyright 2010 IEEE.

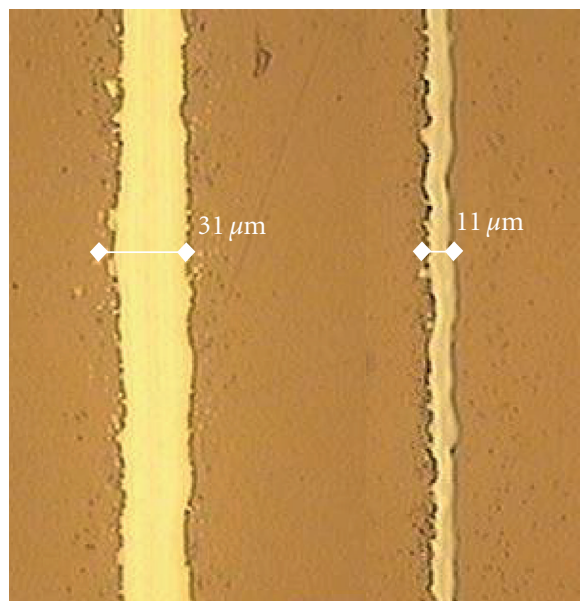

Figure 4: Comparison of A-DW printed lines made with Aerosol Jet (left) and CAB-DW (right) under identical print parameters (25 sccm carrier gas, $15 \mathrm{sccm}$ sheath gas, $2 \mathrm{~mm}$ stand-off height, $30 \mathrm{~mm} / \mathrm{s}$ translation), from Schulz et al. [18], Copyright 2010 IEEE.

lines and CAB-DW produced $11 \mu \mathrm{m}$ wide lines as shown in Figure 4.

2.3. Aerodynamic Lenses with Liquid Aerosol. A new ADW system designed for printing nanoparticles which uses aerodynamic lens for focusing was developed by Qi et al. [15]. The deposition process of this system, represented schematically in Figure 5, begins with the pneumatic atomization of a suspension of CdSe/ZnS core/shell nanocrystals in hexane. The aerosol is focused through aerodynamic lenses and directed into an evacuated chamber and onto a substrate that is translated with an $x-y$ stage. Microtowers and microlines $158 \mu \mathrm{m}$ tall by $27 \mu \mathrm{m}$ wide and $2.9 \mu \mathrm{m}$ tall by $7 \mu \mathrm{m}$ wide were deposited onto sapphire, glass, and silicon substrates with examples shown in Figure 6. The microlines were printed at a translation speed of $10 \mu \mathrm{m} / \mathrm{s}$, much lower than Aerosol Jet and CAB-DW, but this system may still be valuable because unlike Aerosol Jet and CABDW, nanoparticles can be successfully focused. In addition, the system is reliable and inexpensive using standard aerosol lenses without the need for a sheath gas. The system however will have challenges in commercialization due to the low deposition rate and that printing is required to be performed in an evacuated system. Such evacuated systems are however commonly used in microelectronics fabrication [15].

2.4. Microcold Spray-Solid Aerosols through Nozzles. Cold spray was developed in the early 1980s by Papyrin et al. [19] who was experimenting with two-phase supersonic flow and found that at certain critical velocities particles would adhere to surfaces. This adherence is caused when the aerosol particle impacts the substrate at a velocity great enough to cause plastic deformation of the particle and/or substrate which results in a localized heating and high pressure region creating intimate contact between the particle and substrate. The critical velocity is dependent on a combination of the particle material, substrate material, particle temperature prior to impaction, and particle size. Critical velocities for copper, iron, nickel, and aluminum are reported to be $\sim 570,630,630$, and $690 \mathrm{~m} / \mathrm{s}$, respectively [20]. Cold spray technology was developed into a commercial system designed for thin film deposition in $2001[19,21]$.

The ability to focus the spray to small $(<100 \mu \mathrm{m})$ dimensions gives beams of material and substantiates the term microcold spray (MCS) direct-write. An advantage of MCS of circuit metallization/interconnects is that the deposited materials require no postprocessing. Building from our previous experimental-analytical comparison of liquid aerosols [11], MCS incorporates a nozzle system to deposit lines of ductile metals that exhibit conductivities that reach $90 \%$ of the bulk values. Figure 7 is a schematic diagram of the NDSU MCS system helium gas which first passes through one of two mass flow controllers (MFCs). The outlet of the first MFC passes through a powder feeder where solid particles are aerosolized into the $\mathrm{He}$, creating a carrier gas stream (Figure 7(a)). The second MFC controls the $\mathrm{He}$ accelerator gas flow to around 2 LPM (versus $100 \mathrm{sccm}$ for the carrier). Each of these streams then enters the deposition head (Figure 7(b)) where both are heated to offset the cooling effect of gas acceleration. The two streams interact in the flow-cone section of the deposition head and finally pass through a converging nozzle. Nozzle diameters of 100 to $200 \mu \mathrm{m}$ are commonly employed, and a multinozzle system could also be adopted.

2.5. Atomization Methods. One major challenge with any aerosol print system is the atomization process. Although it may be easy to atomize many materials, the process of focusing aerosol particles for A-DW requires a monodisperse aerosol with uniform properties over long periods of time for good print quality. The ultrasonic techniques mentioned previously for A-DW applications produce a relatively monodisperse aerosol but have a limited ability to atomize viscous materials and suffer from long-term changes in atomization due to factors such as ink drying and heat. Other manufacturers such as Sono-Tek [22] and Sonaer Ultrasonics [23] have developed ultrasonic horn aerosol generators which are capable of creating aerosol particles with mean droplet diameter as small as $13 \mu \mathrm{m}$ and $11.8 \mu \mathrm{m}$, respectively, but have a Gaussian droplet size distribution. Sono-Tek's atomization system was even developed into an 


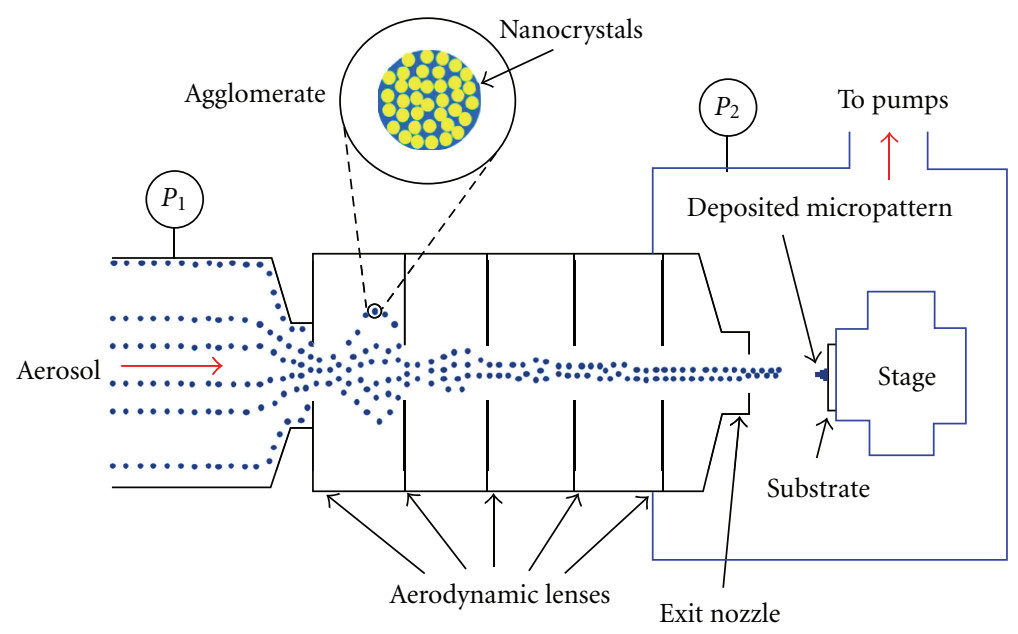

FIgURE 5: Schematic of A-DW focused particle beam deposition system, from Qi et al. [15], Aerosol Science and Technology, Copyright 2010, Mount Laurel, NJ. Reprinted with permission.

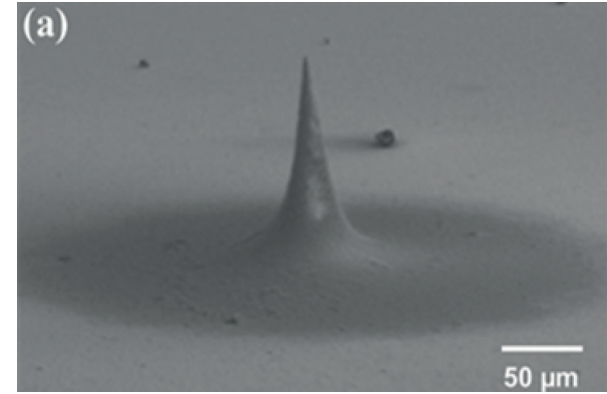

(a)

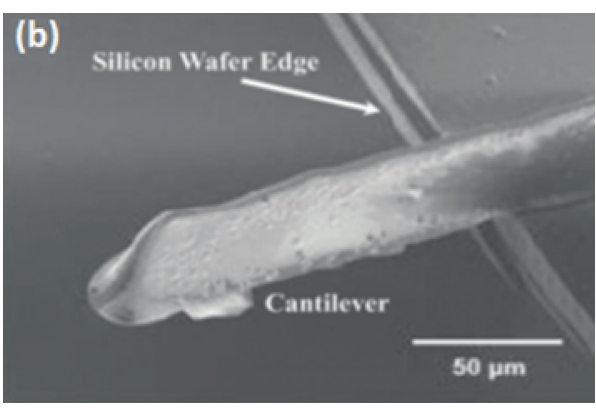

(b)

Figure 6: SEM image of CdSe/ZnS core/shell nanocrystal-based features printed using aerodynamic lenses; (a) microtower, (b) microline, from Qi et al. [15], Aerosol Science and Technology, Copyright 2010, Mount Laurel, NJ. Reprinted with permission.

A-DW system using their atomizer termed MicroMist which is able to spray features as thin as $400 \mu \mathrm{m}$ when coupled to a precision translation system [22]. Tsai et al. [24] developed a Fourier horn atomizer built from silicon which is capable of producing near monodisperse particles with a droplet diameter of $7.0 \mu \mathrm{m}$. Ju et al. [25] and Qi et al. [26] describe a surface acoustic wave (SAW) atomizer capable of producing micron-sized droplets similar to what is required for directwrite applications. More details into the physics behind these atomizers are beyond the scope of this paper but have been reviewed by Friend and Yeo [27]. Overcoming challenges related to any atomization process are still ongoing, with future developments of more monodisperse aerosol generation techniques poised to greatly impact all A-DW processes.

2.6. Materials for Atomization. For any A-DW technology, the printing materials are of great importance. For MCS micron-sized powder is sufficient. For Aerosol Jet and CABDW the deposition materials are slightly more complicated. The inks must be atomizable, provide necessary print characteristics such as minimal overspray and good substrate adhesion, and transformable to the desired final characteristics (i.e., low resistivity, continuous, stable) using methods compatible with the substrate. Kim and Han [28] review briefly the attributes required for A-DW inks and some examples of commercial suppliers. Many inks require a high sintering temperature $\left(400^{\circ} \mathrm{C}\right)$ in order to achieve near bulk conductivity. This temperature is much too high for flexible polymeric substrates which are damaged at temperatures above $150^{\circ} \mathrm{C}$. Some manufacturers produce inks with lower sintering temperatures $\left(<100^{\circ} \mathrm{C}\right)$ for flexible applications while still maintaining a reasonable conductivity. Conductive inks are available commercially through several manufacturers including Cima Nanotech (St. Paul, Minnesota USA), NanoMas (Endicott, NY USA), UT Dots Inc. (Champaign, IL USA), Applied Nanotech (Austin, TX USA), Novacentrix (Austin, TX USA), Cabot Corporation (Boston, MA USA), Harima Chemicals (Osaka, Japan), Advanced Nano Products (Korea), and P.V. Nanocell (Migdal Ha'Emek, Israel). Many of the inks produced are silver or copper based and are designed for inkjet or screen printing applications but can be reduced with solvents to an appropriate viscosity for A-DW. The correct ink for each application must be selected based on the aforementioned qualities. In many circumstances, the specific ink formulation is determined in a trial-anderror process to develop the best overall printed features which balance print quality against the physical and electrical performance. 


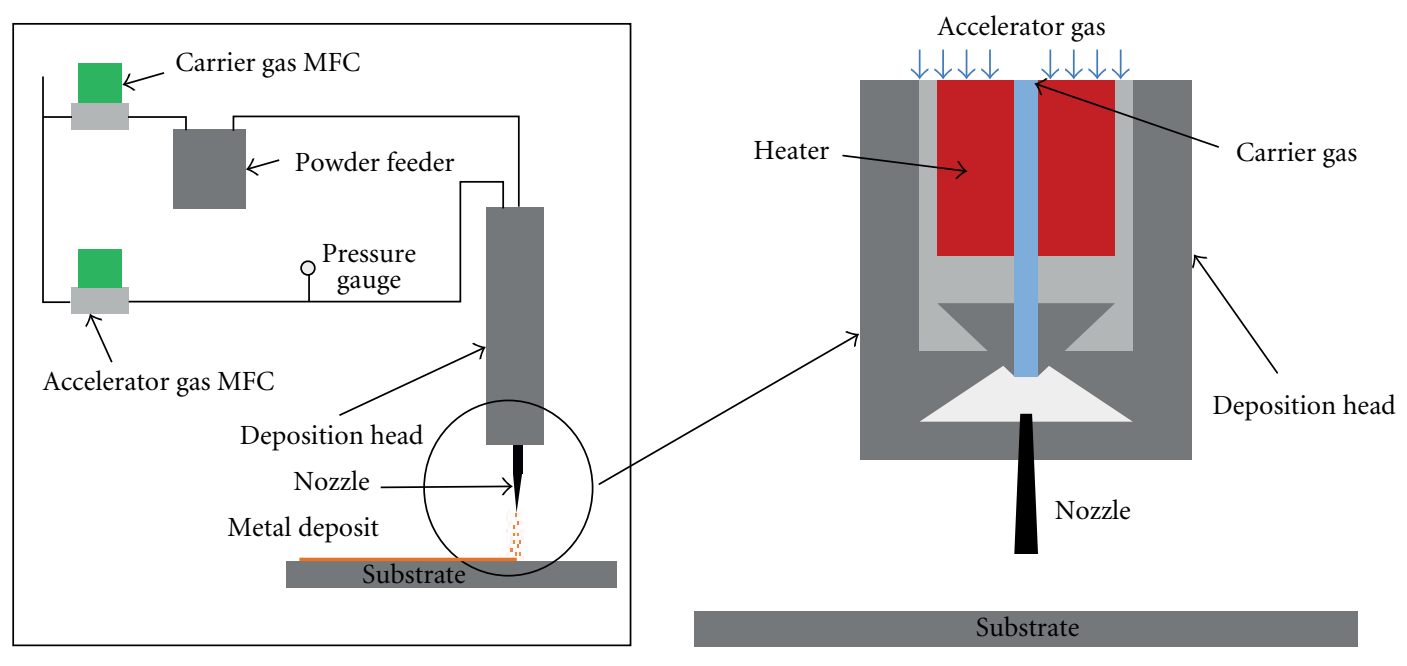

(a)

(b)

FIGURe 7: Schematic diagram of (a) the MCS system for solid aerosols, (b) MCS deposition head, from Bhattacharya et al. [11], Copyright 2012 ASME. Reprinted with permission.

2.7. A-DW Systems Summary. The ability to understand and model aerosol flow physics and compare to experimental designs is paramount in improving aerosol direct-write technology. All A-DW technologies still suffer from minor overspray and nonoptimum line width. One challenge with liquid aerosol technologies is not in the printing itself, but rather in the ink formulation. For example, metal traces can be printed using nanoparticle or metalorganic-based inks, but after deposition, the inks must be postprocessed. This postprocessing adds an additional cost to the overall process and can limit the ability to print on some temperaturesensitive substrates. In addition, a subbulk conductivity due to porosity of the deposits and incomplete sintering is common. If these difficulties are overcome with improved aerosol focusing and ink technology, the applications of A-DW will greatly benefit from the decreased feature size and increased conductivity afforded. Table 1 summarizes the main characteristics of the A-DW technologies including line width, deposition speed, special requirements, and whether postprocessing is required.

\section{Physics of Aerosols}

3.1. Sum of Forces on Aerosols. A fundamental understanding of the physics of the aerosol fluid interaction is the foundation to improved deposition characteristics (i.e., focus, collimation, line width, reduced overspray) for all A-DW methods. Indeed, such insight can lead to novel technologies as illustrated by CAB-DW and MCS. Modeling of aerosolfluid interactions is not new, with models dating back to Stokes' work in 1851. The movement of aerosol particles can be determined by these aforementioned forces applied to Newton's 2nd law where force equals mass times acceleration as shown below:

$$
\frac{4}{3} \pi a^{3} \rho_{p} \frac{d \mathbf{v}_{p}}{d t}=\sum \mathbf{F}
$$

where $a$ is the particle radius, $\rho_{p}$ is the particle density, $\mathbf{v}_{p}$ is the velocity vector of the particle, and $\sum \mathbf{F}$ is the sum of all forces acting on the aerosol particle. Many forces acting on a particle in a fluid have been developed, but in general seven forces are commonly used for modeling of the fluid-particle interaction of aerosols:

$$
\sum \mathbf{F}=\mathbf{F}_{\mathrm{St}}+\mathbf{F}_{\mathrm{Ba}}+\mathbf{F}_{\mathrm{Vm}}+\mathbf{F}_{\mathrm{Ps}}+\mathbf{F}_{\mathrm{Gr}}+\mathbf{F}_{\mathrm{Ma}}+\mathbf{F}_{\mathrm{Sa}},
$$

where $\mathbf{F}_{\mathrm{St}}$ is Stokes force (steady viscous drag force), $\mathbf{F}_{\mathrm{Ba}}$ is Basset force (nonsteady viscous drag force), $\mathbf{F}_{\mathrm{Vm}}$ is the virtual mass force (inertia of fluid surrounding particle added to particle), $\mathbf{F}_{\mathrm{Ps}}$ is the pressure gradient force, $\mathbf{F}_{\mathrm{Gr}}$ is the buoyancy force caused by gravity, $\mathbf{F}_{\mathrm{Ma}}$ is the Magnus lift force due to particle rotation, and $\mathbf{F}_{\mathrm{Sa}}$ is the Saffman lift force on a particle with local shear flow [8, 29-37]. It is understood that there are several other forces which may act on aerosol particles in certain circumstances including Brownian diffusion, thermophoresis, diffusiophoresis, photophoresis, electromagnetic radiation pressure, acoustic pressure, electrostatic, and van der Waals [38]. For the applications discussed here, impact of the forces on the aerosol particles is minimal as they are not due to fluidparticle interactions and hence are out of the scope of this paper.

Sir George Gabriel Stokes [39] developed the first theoretical model for the forces acting on spherical aerosol particles in a viscous fluid under laminar flow conditions. Stokes solved the equations of motion (Navier-Stokes) for laminar flow around a cylinder and sphere and integrated the forces applied to the surface of the body. Stokes found the force on a particle, $\mathbf{F}_{\mathrm{St}}$ :

$$
\mathbf{F}_{\mathrm{St}}=6 \pi a \mu_{f}\left(\mathbf{v}-\mathbf{v}_{p}\right)
$$

where $\mu_{f}$ is the fluid viscosity and $\left(\mathbf{v}-\mathbf{v}_{p}\right)$ is the fluid velocity relative to the moving particle [40-42]. 
TABLE 1: Summary of A-DW technology print system characteristics.

\begin{tabular}{lcccccc}
\hline Method & $\begin{array}{c}\text { Minimum line } \\
\text { width }(\mu \mathrm{m})\end{array}$ & $\begin{array}{c}\text { Deposition } \\
\text { speed }(\mathrm{mm} / \mathrm{s})\end{array}$ & Vacuum requirement & $\begin{array}{c}\text { Overspray } \\
\text { scrubber required }\end{array}$ & VOC concern & $\begin{array}{c}\text { Postprocessing } \\
\text { required }\end{array}$ \\
\hline Aerosol Jet & $<10$ & 200 & No & Yes & Yes & Yes \\
CAB-DW & $<5$ & 200 & No & Yes & Yes & Yes \\
Aerodynamic lenses & $\sim 10$ & 0.01 & Yes & Yes & Yes & No \\
MCS & 50 & $>10^{*}$ & No & Yes & No & No \\
\hline
\end{tabular}

* Deposition speeds greater than $10 \mathrm{~mm} / \mathrm{s}$ are possible but have not been experimentally validated.

The Basset force is defined as $[31,32,34]$

$$
\mathbf{F}_{\mathrm{Ba}}=6 a^{2} \sqrt{\pi \mu_{f} \rho_{f}} \int_{0}^{t}\left(\frac{d \mathbf{v} / d t-d \mathbf{v}_{p} / d t}{\sqrt{t-\tau}}\right) d \tau
$$

where $\rho_{f}$ is the density of the fluid.

Assuming a simple model with constant acceleration, Chao Zhu and Liang-Shih Fan in the CRC Handbook of Fluid Dynamics [43] mentioned that the ratio of the Basset force to the Stokes force looks as follows:

$$
\varepsilon_{\mathrm{Ba}}=\frac{\left|\mathbf{F}_{\mathrm{Ba}}\right|}{\left|\mathbf{F}_{\mathrm{St}}\right|}=\sqrt{\frac{18}{\pi} \frac{\rho_{f}}{\rho_{p}} \frac{\tau_{\mu}}{t}},
$$

where $\tau_{\mu}$ is the Stokes relaxation time: $\tau_{\mu}=2 a^{2} \rho_{p} / 9 \mu_{f}$.

Marshall [33] found that the ratio of the Basset force to the drag force can be expressed as

$$
\frac{\left|\mathbf{F}_{\mathrm{Ba}}\right|}{\left|\mathbf{F}_{\mathrm{St}}\right|} \cong \operatorname{Re}_{p}^{1 / 2} \ll 1,
$$

where $\operatorname{Re}_{p}$ is the Reynolds number of the particle with respect to the fluid:

$$
\operatorname{Re}_{p} \equiv \frac{2 a \rho_{f}\left|\mathbf{v}-\mathbf{v}_{p}\right|}{\mu_{f}} .
$$

The virtual mass force, $\mathbf{F}_{\mathrm{Vm}}$, is given by $[29,33]$

$$
\mathbf{F}_{\mathrm{Vm}}=-c_{M} \frac{\rho_{f}}{\rho_{p}} m\left(\frac{d \mathbf{v}}{d t}-\frac{d \mathbf{v}_{p}}{d t}\right),
$$

where $m$ is the mass of the particle and $c_{M}$ is the added mass coefficient, which is equal to 0.5 for a sphere.

The pressure gradient force, $\mathbf{F}_{\mathrm{Ps}}$, due to the acceleration of the external flow past the particle, is calculated by the following equation $[29,33]$ :

$$
\mathbf{F}_{\mathrm{Ps}}=m \frac{\rho_{f}}{\rho_{p}} \frac{D \mathbf{v}}{D t},
$$

where $D / D t$ denotes the rate of change with time following a fluid particle, such that

$$
\frac{D \mathbf{v}}{D t}=\frac{d \mathbf{v}}{d t}-\left[\left(\mathbf{v}_{p}-\mathbf{v}\right) \cdot \nabla\right] \mathbf{v} .
$$

The buoyancy force, $\mathrm{F}_{\mathrm{Gr}}$, due to gravity is equal to

$$
\mathbf{F}_{\mathrm{Gr}}=m\left(1-\frac{\rho_{f}}{\rho_{p}}\right) \mathbf{g},
$$

where $\mathbf{g}$ is the acceleration vector due to gravity.
Magnus force, $\mathbf{F}_{\mathrm{Ma}}$, is present if the particle is in rotation with respect to the surrounding fluid and is given by $[31,33]$

$$
\mathbf{F}_{\mathrm{Ma}}=-\frac{3}{4} m \frac{\rho_{f}}{\rho_{p}}\left(\frac{1}{2} \omega-\Omega\right) \times\left(\mathbf{v}_{p}-\mathbf{v}\right),
$$

where $\omega$ is the vorticity of the fluid surrounding the particle and $\Omega$ is the angular rate of rotation of the particle. Based on the analysis given in [43], it can be noted that the ratio of Magnus force to Stokes force is equal to

$$
\varepsilon_{\mathrm{Ma}}=\frac{\left|\mathbf{F}_{\mathrm{Ma}}\right|}{\left|\mathbf{F}_{\mathrm{St}}\right|}=\frac{a^{2} \rho_{f}|(1 / 2) \omega-\Omega|}{6 \mu_{f}} .
$$

Assuming that the fluid flow is nonrotational and the aerosol particle rotates due to local shear of the carrier flow, $|(1 / 2) \omega-\Omega| \approx|\partial u / \partial y| \approx U / R$, this ratio of Magnus force to Stokes force can be further simplified to

$$
\varepsilon_{\mathrm{Ma}} \cong \frac{a^{2} \rho_{f} U}{6 \mu_{f} R},
$$

where $u$ is the gas axial velocity component, $U$ is the mean velocity of the fluid flow through the capillary, and $R$ is the radius of the capillary. Therefore, the ratio $\varepsilon_{\mathrm{Ma}}$ is about $10^{-3}$, assuming aerosol particles of $1 \mu \mathrm{m}$ diameter moving in nitrogen at standard conditions with mean velocity of $50 \mathrm{~m} / \mathrm{s}$ through a capillary of $100 \mu \mathrm{m}$ radius.

Saffman force, $\mathrm{F}_{\mathrm{Sa}}$, is a lift force applied to aerosol particles in a simple laminar shear flow (Poiseuille flow) and was developed by P. G. Saffman in 1965 [36]. The lift is proportional to the rate of shear and the magnitude of the relative velocity of the particle with respect to the fluid:

$$
\mathbf{F}_{\mathrm{Sa}}=6.46 a^{2}\left(u-u_{p}\right) \sqrt{\rho_{f} \mu_{f}\left|\frac{\partial u}{\partial y}\right|} \operatorname{sign}\left(\frac{\partial u}{\partial y}\right) \mathbf{e}_{y},
$$

where the value 6.46 is a constant from numerical integration determined in the addendum of Saffman [36], $u$ is the gas axial velocity component, and $u_{p}$ is the particle axial velocity component.

A detailed estimation of the ratio between the Saffman force and the Stokes force in aerosol focusing was given in [8] where Akhatov et al. calculated that

$$
\varepsilon_{\mathrm{Sa}}=\frac{\left|\mathbf{F}_{\mathrm{Sa}}\right|}{\left|\mathbf{F}_{\mathrm{St}}\right|} \approx 0.3 \frac{a}{R} \sqrt{\operatorname{Re}_{c}}, \quad \operatorname{Re}_{c}=\frac{2 R U \rho_{f}}{\mu_{f}} .
$$

Based on their analysis, it was found that $\varepsilon_{S_{a}}$ was about 0.05 . 
Similar results for the ratio of the Saffman force to the Stokes drag force are given by Chao Zhu and Liang-Shih Fan in the Handbook of Fluid Dynamics [43]:

$$
\varepsilon_{\mathrm{Sa}}=\frac{\left|\mathbf{F}_{\mathrm{Sa}}\right|}{\left|\mathbf{F}_{\mathrm{St}}\right|}=\frac{6.46 a}{6 \pi} \sqrt{\frac{\rho_{f}}{\mu_{f}}\left|\frac{\partial\left(u-u_{p}\right)}{\partial y}\right|},
$$

where the simplified form of the Saffman to Stokes force ratio can be presented by the equation below assuming simple shear flow:

$$
\varepsilon_{\mathrm{Sa}}=\frac{\left|\mathbf{F}_{\mathrm{Sa}}\right|}{\left|\mathbf{F}_{\mathrm{St}}\right|}=\frac{6.46}{12 \pi} \sqrt{\operatorname{Re}_{p}}, \quad \operatorname{Re}_{p}=\frac{2 a \rho_{f}\left|\mathbf{v}-\mathbf{v}_{p}\right|}{\mu_{f}} .
$$

The forces acting on the aerosol particles are only important if they are appreciable as compared to Stokes force. For the analysis of aerosol particles of $0.5-5 \mu \mathrm{m}$, gravity force is not appreciable. Marshall found that the Basset force may be ignored [33]. Crowe et al. [31] found that the pressure gradient force, virtual mass force, and Basset force may also be ignored. Akhatov et al. agree with this elimination of forces and summarize that the two most valuable forces are Stokes and Saffman [8].

3.2. Stokes Correction Factor for Rarefied Gases. Stokes drag force assumes a linear dependence of the force on the relative velocity of the particle to the fluid (lag). A linear dependence is applicable for many particle-fluid combinations but experimental deviations in certain situations such as in rarified flows needed to be addressed if the particle size is small $(<0.5 \mu \mathrm{m})$. Several models for the lag, including those by Cunningham [44] and a more revised model by Carlson and Hoglund [45] that take into account the gas slip on the particle surface due to gas rarefication (based on Knudsen number) and the magnitude of the relative velocity of the particles with respect to the fluid, have been devised.

Cunningham [44] related the variation in Stokes force to the Knudsen number by

$$
F_{\text {Stokes } C c}=\frac{F_{\text {Stokes }}}{1+A^{\prime} K n},
$$

where $K n$ is the particle Knudsen number (mean free path/diameter) and $A^{\prime}$ is a nondimensional coefficient. In this model, Stokes force has less of an effect as $K n$ increases due to the slip of the fluid on the particle surface.

Knudsen and Weber [46] discovered that (19) is only valid for very small $K n$. To incorporate large variances in $K n$, three additional parameters were included to generate the Stokes-Cunningham equation:

$$
F_{\text {Stokes } C c}=\frac{F_{\text {Stokes }}}{1+K n_{p}\left(A+B e^{-E / K n_{p}}\right)},
$$

where $A, B$, and $E$ are constants determined experimentally [41, 47].

Table 2 gives a sampling of the many experimental values for the parameters in the Cunningham slip correction factor. Many of the correction factors are based on the oil drop experiments by Millikan [42] where the slip on $0.3 \mu \mathrm{m}$ oil droplets in air was evaluated. The drift velocity of the particles was measured and used to determine the slip correction factors.

3.3. Stokes Correction for Reynolds and Mach Numbers. Stokes drag force acting on a spherical particle, (3), was derived for low Reynolds numbers $\left(\operatorname{Re}_{p} \ll 1\right)$; therefore, if considering the flows of spherical particles with broad range of Reynolds numbers, the Stokes equation should be revised; these corrections are especially critical in modeling applications such as MCS. Clift et al. [56] summarized all empirical and semiempirical drag corrections $C_{D}$ for different ranges of Reynolds number in Table 3 where Stokes force is related to $C_{D}$ according to (21) as follows:

$$
\mathbf{F}_{\mathrm{St}}=\frac{\pi}{2} C_{D} \rho_{f} a^{2}\left(\mathbf{v}-\mathbf{v}_{p}\right)^{2} .
$$

Clift et al. also investigated the drag coefficient correction for Stokes force in the case of solid particles of arbitrary shape (spheroids, disks, cylinders, etc.) and ellipsoidal fluid particles [56], but the dependency of the drag force on the particle shape is beyond the scope of this paper. In general, corrections to Stokes force are not only dependent on the particle shape, orientation to the flow, and Reynolds number but also on Mach number and the turbulence level of the fluid. Carlson and Hoglund [45] devised an improved empirical correction factor based on the particle Reynolds number, $\operatorname{Re}_{p}$, and the Mach number, $M_{p}$, according to (22) as follows:

$$
G=\left(1+\frac{1}{6} \operatorname{Re}_{p}^{2 / 3}\right)\left(1+e^{-0.427 / M_{p}^{4.63}}\right),
$$

where the relative Mach number of the particle compared to the fluid is

$$
M_{p}=\frac{\left|\mathbf{v}-\mathbf{v}_{p}\right|}{C_{g}}, \quad \mathbf{F}_{\mathrm{St}}=6 \pi a \mu_{f} G\left(\mathbf{v}-\mathbf{v}_{p}\right),
$$

and $C_{g}$ is the speed of sound of the gas.

The correction factor of Carlson and Hoglund [45] is similar to that of Schiller and Nauman [57], but with a Mach number correction included for flow compressibility. The constants are also nearly identical with $1 / 6$ replacing 0.15 and $2 / 3$ replacing 0.687 . An even more improved equation has been collected by Wang et al. [58] using the work of $[36,45,53,59]$ which accounts for all of the previously mentioned correction factors:

$$
G=\frac{\left(1+(1 / 6) \operatorname{Re}_{p}^{2 / 3}\right)\left(1+e^{-0.427 / M_{p}^{4.63}-\left(3 / \operatorname{Re}_{p}^{0.88}\right)}\right)}{1+K n_{p}\left(2.57+0.68 e^{-1.86 / K n_{p}}\right)} .
$$

The correction from Schiller and Naumann [57] has been used extensively by several researchers including Wang et al. [60] and Kuan and Schwarz [61] who used it to model gasparticle interactions in vertical ducts. Wang and Osiptsov [62] used the correction of Carlson and Hoglund [45] to model the movement of particles in the laminar region near a wall in a dusty gas shock wave. 
TABLE 2: Stokes-Cunningham slip correction factors, reprinted from Li and Wang [41] http://link.aps.org/doi/10.1103/PhysRevE.68.061206, and Allen and Raabe [48], Copyright 2003 and 1982, with permission from American Physical Society and Elsevier, respectively.

\begin{tabular}{lccccc}
\hline Author, Year & Mean free path $(\mu \mathrm{m})$ & $A$ & $B$ & $E$ & $A+B$ \\
\hline Knudsen and Weber, 1911 [46] & 0.09417 & 0.772 & 0.40 & 1.63 & 1.172 \\
Millikan, 1923 [42] & 0.09417 & 0.864 & 0.29 & 1.25 & 1.154 \\
Langmuir, 1942 [49] & 0.133 & 0.62 & 0.22 & 2.20 & 0.84 \\
Davies, 1945 [50] & 0.066 & 1.257 & 0.40 & 1.10 & 1.657 \\
DeMarcus and Thomas, 1952 [51] & 0.0655 & 1.25 & 0.44 & 1.09 & 1.690 \\
Reif, 1958 [52] & 0.0652 & 1.26 & 0.45 & 1.08 & 1.710 \\
Fuchs, 1964 [53] & 0.0653 & 1.246 & 0.42 & 0.87 & 1.666 \\
Dahneke et al., 1982 [54] & 0.066 & 1.234 & 0.414 & 0.87 & 1.648 \\
Allen and Raabe, 1982 [48] & 0.0673 & 1.155 & 0.471 & 0.596 & 1.626 \\
Buckley and Loyalka, 1989 [55] & - & 1.099 & 0.518 & 0.425 & 1.617 \\
\hline
\end{tabular}

TABle 3: Summary of literature for drag coefficients at different Reynolds numbers, reprinted from Clift et al. [56], Copyright 2005, with permission from Dover Publications, Inc.

\begin{tabular}{|c|c|c|}
\hline Author(s) & Reynolds number range & $C_{D}$ \\
\hline Schiller and Nauman & $\operatorname{Re}_{p}<800$ & $\left(24 / \operatorname{Re}_{p}\right)\left(1+0.15 \operatorname{Re}_{p}^{0.687}\right)$ \\
\hline Lapple & $\operatorname{Re}_{p}<1000$ & $\left(24 / \operatorname{Re}_{p}\right)\left(1+0.125 \operatorname{Re}_{p}^{0.72}\right)$ \\
\hline Langmuir and Blodgett & $1<\operatorname{Re}_{p}<100$ & $\left(24 / \operatorname{Re}_{p}\right)\left(1+0.197 \operatorname{Re}_{p}^{0.63}+2.6 \times 10^{-4} \operatorname{Re}_{p}^{1.38}\right)$ \\
\hline Allen & $2<\mathrm{Re}_{p}<500$ & $10 \operatorname{Re}_{p}^{-1 / 2}$ \\
\hline Allen & $1<\operatorname{Re}_{p}<1000$ & $30 \operatorname{Re}_{p}^{-0.625}$ \\
\hline Gilbert et al. & $0.2<\operatorname{Re}_{p}<2000$ & $0.48+28 \operatorname{Re}_{p}^{-0.85}$ \\
\hline Kurten et al. & $0.1<\operatorname{Re}_{p}<4000$ & $0.28+6 / \operatorname{Re}_{p}^{0.5}+21 / \operatorname{Re}_{p}$ \\
\hline Abraham & $\operatorname{Re}_{p}<6000$ & $0.2924\left(1+9.06 \mathrm{Re}_{p}^{-0.5}\right)^{2}$ \\
\hline Ihme et al. & $\operatorname{Re}_{p}<10^{4}$ & $0.36+5.48 / \operatorname{Re}_{p}^{0.573}+24 / \operatorname{Re}_{p}$ \\
\hline Rumpf & $\operatorname{Re}_{p}<10$ & $2+24 / \operatorname{Re}_{p}$ \\
\hline Rumpf & $\operatorname{Re}_{p}<100$ & $1+24 / \operatorname{Re}_{p}$ \\
\hline Rumpf & $\operatorname{Re}_{p}<10^{5}$ & $0.5+24 / \operatorname{Re}_{p}$ \\
\hline Clift and Gauvin & $\operatorname{Re}_{p}<3 \times 10^{5}$ & $\left(24 / \operatorname{Re}_{p}\right)\left(1+0.15 \operatorname{Re}_{p}^{0.687}\right)+\left(0.42 /\left(1+4.25 \times 10^{4} \operatorname{Re}_{p}^{-1.16}\right)\right)$ \\
\hline Brauer & $\operatorname{Re}_{p}<3 \times 10^{5}$ & $0.4+4 / \mathrm{Re}_{p}^{0.5}+24 / \mathrm{Re}_{p}$ \\
\hline Tanaka and Iinoya & $\operatorname{Re}_{p}<7 \times 10^{5}$ & $\log _{10} G=a_{1} w^{2}+a_{2} w+a_{3}, w=\log _{10} \operatorname{Re}_{p}$ \\
\hline
\end{tabular}

3.4. Saffman Force. It was first noted by Poiseuille [63] that blood cells had a tendency to stay away from blood vessel walls. Segre and Silberberg [64] noticed that spheres in Poiseuille flow would migrate to 0.6 radii from the centerline of the tube. This phenomenon cannot be explained by Stokes force of any variety and/or particle inertia. Rotational motion of the particles could cause a migration to the centerline due to Magnus force, but not away from the centerline because of the flow profile [65]. To explain the lateral migration of particles Saffman [36] first theoretically analyzed simple shear flow. It was determined that four conditions must be met for there to be an appreciable migration of the particles: (1) very small particle Reynolds numbers, (2) very small shear Reynolds number around the particles, (3) the ratio of the square root of the Reynolds number of the fluid over the Reynolds number of the particle much greater than one, and
(4) the rotational velocity of the particle must be small [36]. The four conditions are described below:

$$
\begin{gathered}
\operatorname{Re}_{p}=\frac{\left|u-u_{p}\right| 2 a \rho_{f}}{\mu_{f}} \ll 1, \quad \operatorname{Re}_{f}=\frac{\rho_{f}(2 a)^{2}}{\mu_{f}}\left|\frac{\partial u}{\partial y}\right| \ll 1, \\
\varepsilon=\frac{\sqrt{\operatorname{Re}_{f}}}{\operatorname{Re}_{p}} \gg 1, \quad \operatorname{Re}_{\Omega}=\frac{\Omega \rho_{p}(2 a)^{2}}{\mu_{f}} \ll 1,
\end{gathered}
$$

where $\Omega$ is the rotational velocity of the particle and $\operatorname{Re}_{\Omega}$ is the rotational Reynolds number of the particle. Saffman derived the force acting on the particles in a simple shear flow (laminar flow) and further developed the equation for the force in Poiseuille flow in a tube. 


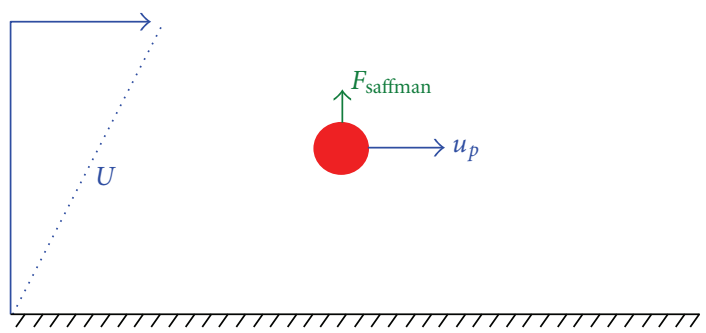

FIGURE 8: Schematic illustrating direction of Saffman force in shear flow.

A diagram of the direction of Saffman force acting on a particle with a velocity less than that of the fluid can be seen in Figure 8. Notice that the particle is forced towards increasing velocity. Saffman [36] specified that the force is in the direction of increasing velocity for lagging particles and decreasing velocity for leading particles. Also, the force acting on the particles is increased with an increased fluid velocity gradient and fluid velocity relative to the particle. The direction of Saffman force was verified when compared to the results of Oliver [66]. Oliver found that settling particles in a downward flowing liquid would migrate towards the wall of the tube. Conversely, floating particles would migrate towards the axis in downward flowing liquid. This phenomenon can be explained by the effects of Saffman force.

3.5. Saffman Force Corrections. As with Stokes force, Saffman force requires corrections to be applicable in many situations such as larger Reynolds number. An equation to model the Saffman force under higher Reynolds numbers was devised by Mei [59]. The model is based on work performed by Dandy and Dwyer [67] who used a three-dimensional numerical simulation to model linear shear flow past a small sphere. It was noted that the shear force coefficient (Saffman force) was near constant for intermediate gas Reynolds numbers and proportional to the square root of the gas Reynolds number for particle Reynolds numbers less than 40 as seen below:

$$
\begin{gathered}
\frac{C_{L}}{C_{L S a}}=\left(1-0.3314 \alpha^{1 / 2}\right) e^{-\mathrm{Re}_{p} / 10}+0.3314 \alpha^{1 / 2}, \quad \operatorname{Re}_{p} \leq 40, \\
\frac{C_{L}}{C_{L S a}}=0.0524\left(\alpha \operatorname{Re}_{p}\right)^{1 / 2}, \quad \operatorname{Re}_{p}>40,
\end{gathered}
$$

where the correction factors used for Saffman force are the coefficient of lift, $C_{L}$

$$
C_{L}=\frac{F_{L}}{(1 / 2) \rho_{f} \pi a^{2} u^{2}},
$$

and $\alpha$ :

$$
\alpha=\frac{1}{2} \operatorname{Re}_{p} \varepsilon^{2} .
$$

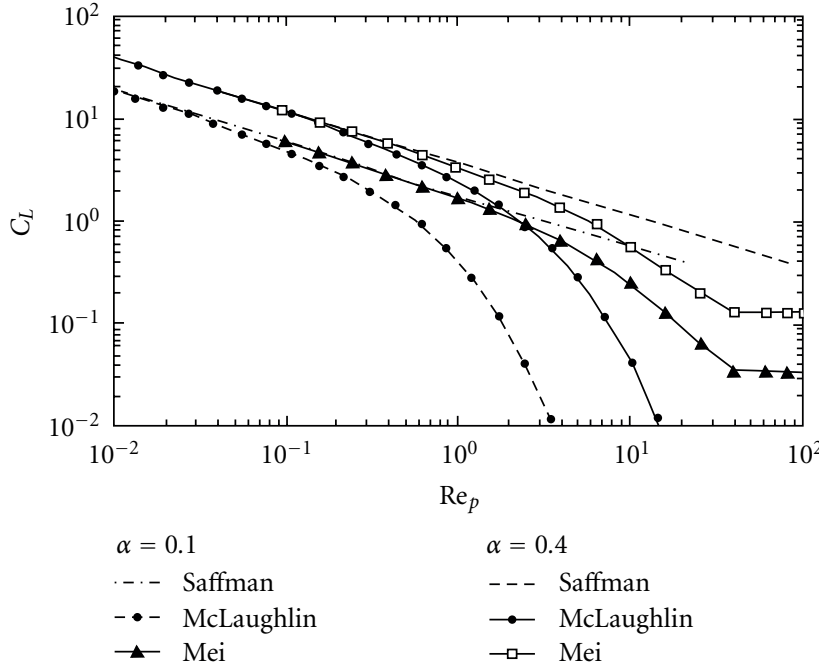

FIGURE 9: Graph of shear coefficient versus Reynolds number based on the analyses of Mei [59], McLaughlin [69], and Saffman [36], reprinted from Mei [59], Copyright 1992, with permission from Elsevier.

The correction from [59] used in $[8,58,62,68]$ can be further expressed:

$$
H=\left\{\begin{array}{cc}
0.23434\left(1-e^{-0.1 \mathrm{Re}_{p}}\right) \sqrt{\frac{\operatorname{Re}_{f}}{\operatorname{Re}_{p}}}+e^{-0.1 \mathrm{Re}_{p}}, & \operatorname{Re}_{p} \leq 40 \\
0.0371 \sqrt{\operatorname{Re}_{f}}, & \operatorname{Re}_{p}>40
\end{array}\right\},
$$

where Saffman force is then

$$
\mathbf{F}_{\mathrm{S} a}=6.46 H a^{2}\left(u-u_{p}\right) \sqrt{\rho_{f} \mu_{f}\left|\frac{\partial u}{\partial r}\right|} \operatorname{sign}\left(\frac{\partial u}{\partial r}\right) \mathbf{e}_{y} .
$$

McLaughlin investigated the Saffman force correction for higher Reynolds numbers $\left(\operatorname{Re}_{f}, \operatorname{Re}_{p}\right)$ in [69] and reported the correction data table in the case when $0.025 \leq \varepsilon \leq \infty(\varepsilon=$ $\left.\sqrt{\operatorname{Re}_{f}} / \operatorname{Re}_{p}\right)$. Mei in [59] further analyzed the McLaughlin tabular data for the range $0.1 \leq \varepsilon \leq 20$ and proposed to use the following function to fit the correction data:

$$
\begin{aligned}
\frac{C_{L}}{C_{L S a}}= & 0.443 \times 0.6765\left[1+\tanh \left(2.5 \log _{10} \varepsilon+0.191\right)\right] \\
& \times\{0.667+\tanh [6(\varepsilon-0.32)]\} .
\end{aligned}
$$

A comparison of Saffman force and the correction factors proposed by Mei [59], along with work by Mclaughlin [69], can be seen in Figure 9. Notice that Saffman force is linear throughout the log-log plot. Mei's correction factor was close to Saffman for small Reynolds numbers. After a Reynolds number greater than approximately 5, the correlation departed from Saffman force. The ability to use Mei's correlation allowed for much greater Reynolds numbers for Saffman force. In fact, Reynolds numbers as high as 1000-1100 have been used [70]. 


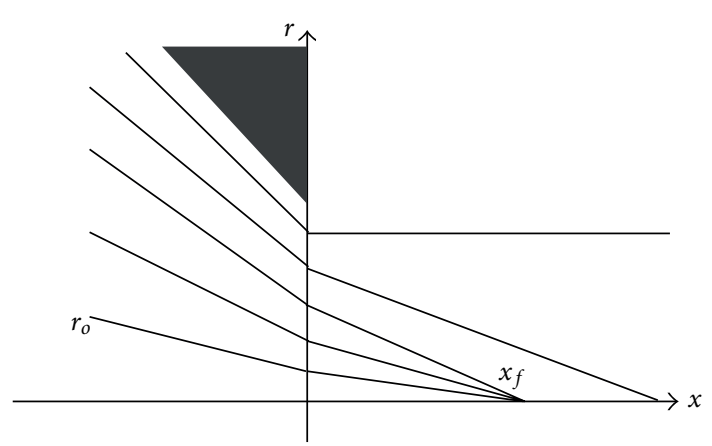

FIGURE 10: Diagram of particles at initial seeded radius, $r_{o}$, exiting nozzle and focused at a distance, $x_{f}$, from the nozzle (after [40]).

\section{Theoretical Application of Forces}

4.1. Stokes Force. Aerosol focusing has been extensively studied in supersonic jets with very large Reynolds numbers. Much of the research has been provided by Cheng and Dahneke [71], Dahneke et al. [54], and Fernandez de la Mora and Riesco-Chueca [40]. It was assumed by these experimenters that particle focusing occurs strictly due to inertial effects and Stokes force, where one would infer that Saffman force is not applicable.

Fernandez De La Mora and Riesco-Chueca [40, 72] found that the focusing of the particles depended on the Stokes number which relates the amount of coupling that the particles have with the fluid by a characteristic time, $\tau_{\mu}$, divided by a characteristic length, $\tau_{L}$ :

$$
\mathrm{St}=\frac{\tau_{\mu}}{\tau_{L}}, \quad \tau_{\mu}=\frac{2 a^{2} \rho_{p}}{9 \mu_{f}}, \quad \tau_{L}=\frac{L}{U},
$$

where $L$ is the fluid characteristic length scale, and Stokes number is calculated as follows:

$$
\text { St }=\frac{2 \rho_{p} a^{2} U}{9 \mu_{f} L} \text {. }
$$

It should be noted that larger Stokes numbers correlate to particles which have less of a tendency to follow the flow. It was found (Israel and Friedlander [73], Israël and Whang [74], Stoffels [75], Sinha et al. [76], Estes et al. [77], Kievit et al. [78], Reents et al. [79], Mallina et al. [47], and Li and Wang [41]) that focusing of particles in a nozzle is mainly dictated by the Stokes number which is in agreement with Fernandez De La Mora and Riesco-Chueca [40, 72]. The focal point distance from the exit of the nozzle, $x_{f}$, as seen in Figure 10 depends on the Stokes number and the initial seeded radial position, $r_{o}[80]$. The focal point moves towards infinity as the Stokes number reaches a critical Stokes number $S^{*}$ (approximately 1).

Rao et al. [80] conducted his experiment with moderate Reynolds numbers (3 to 1000) and noticed that the focusing effects under flows in the viscous regime may actually be greater than those of potential flows. This understanding came about with only Stokes force considered acting on the particles. Mallina et al. [47] describe the focusing

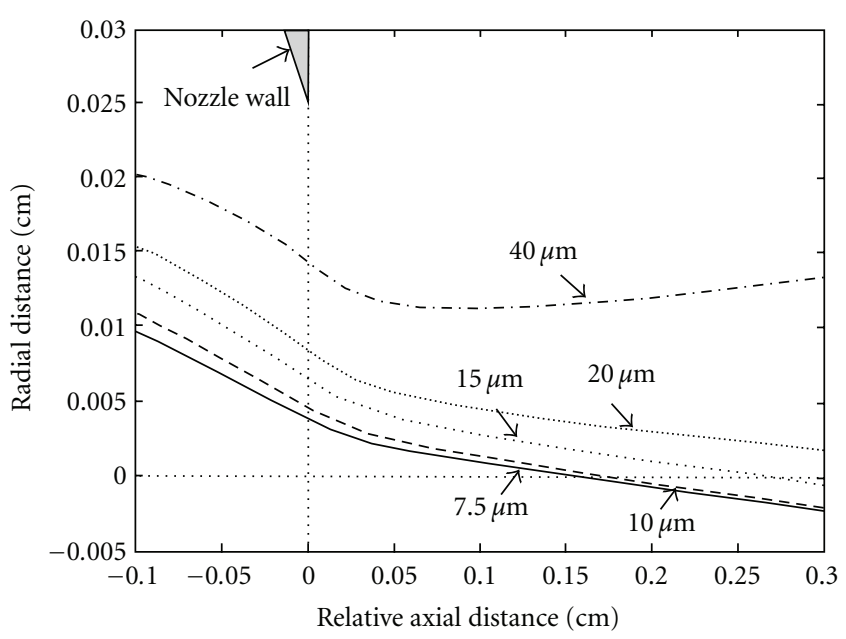

FIGURE 11: Diagram of trajectories for 7.5-40 $\mu \mathrm{m}$ diameter particles exiting a $500 \mu \mathrm{m}$ nozzle, reprinted from Mallina et al. [47], Copyright 1999, with permission from Elsevier.

mechanisms applicable to nozzles and capillaries where focusing can be predicted by the Stokes number, with a Cunningham correction factor. A diagram of the aerosol focusing through a nozzle of $500 \mu \mathrm{m}$ diameter can be seen in Figure 11. Notice that larger particles focus at increasing distances from the nozzles, up until a critical diameter where focusing no longer occurs. In this case, all particles were seeded at $0.1 R_{o}$, where $R_{o}$ is initial radius of the capillary. A similar experiment was done for a capillary of $500 \mu \mathrm{m}$ in diameter and $32 \mathrm{~cm}$ in length by Cheng and Dahneke [71].

Liu et al. [81, 82], Di Fonzo et al. [83], Wang and McMurry [84], and several others designed aerodynamic lens systems that collimate aerosol beams using a series of thin plates. Many of the systems were designed for low pressure and particles in the nanometer range. Modeling of the aerosol particles was done using only Stokes force where it was found that a continuum approximation was only applicable for $K n<0.1$. Wang and McMurry [84] later designed a computer program which determines the correct parameters for an aerodynamic lens system. Parameters such as flow rate, pressure, diameter of the lenses, and spacing between lenses were optimized to provide a collimated aerosol stream of polydisperse particle. The program used values obtained by numerical simulations of the flow of aerosol particles through the lens system. A diagram of an example lens system is shown in Figure 12. Typical values for the flow rate, pressure, length between nozzles, and nozzle diameters are $100 \mathrm{sccm}, 93-600 \mathrm{~Pa}, 10-20 \mathrm{~mm}$, and 1.26$3.2 \mathrm{~mm}$, respectively. There are usually 3 to 5 lenses, but as many as 10 have been commonly used. Particle sizes range from 3 to $250 \mathrm{~nm}$, but particles as large as $3 \mu \mathrm{m}$ have been used in lens systems by others $[84,85]$.

Rao et al. [80] noticed that focusing of particles is reduced due to a "geometric aberration effect." The effect is caused by particles which are seeded into the nozzle at varying radii. The particles focused at different locations along the axis, causing a dull focal point. Focusing was 


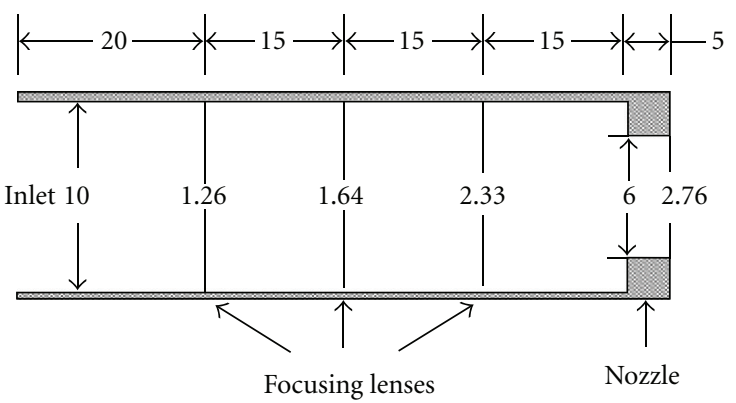

Figure 12: Schematic of aerodynamic lens system for focusing aerosol particles (dimensions in $\mathrm{mm}$ ), from Wang et al. [85], Aerosol Science and Technology, Copyright 2005, Mount Laurel, NJ. Reprinted with permission.

improved by seeding the aerosol particles closer to the axis with a clean air sheath gas. For Rao's experiments, a 50\% sheath gas was used to aid in achieving a focus of less than $2 \%$ of the nozzle diameter. These results were accomplished with a thin-plate nozzle with a diameter on the order of $1 \mathrm{~mm}$. Renn et al. [88] modeled the focusing of aerosol particles through a $100 \mu \mathrm{m}$ nozzle with variable sheath gas using only Stokes force and particle inertia. They proposed that the focusing of aerosol particles is dependent on the particles' Stokes number. Particles with high Stokes numbers, which in this case are particles around $1 \mu \mathrm{m}$ in diameter and larger, would converge and deposit on a substrate. Particles less than $1 \mu \mathrm{m}$ in diameter will follow the flow streamlines and not deposit on the substrate. Good evidence that a focusing mechanism was missing came from Renn et al. [16], where the beamwidth of aerosol particles exiting a $100 \mu \mathrm{m}$ nozzle was compared to a simulation. In this case, the actual focusing was much better than the predicted focusing with particle beams focused to 5-10X smaller than the nozzle diameter [4].

4.2. Saffman Force. Most research using Saffman force is for applications of particles flowing over a flat plate or in a long capillary. We have however included Saffman force in modeling of aerosol focusing for direct-write applications $[8,68]$. Lipatov et al. [70, 89] described a situation similar to Oliver's [66], where it was found that heavy particles in a downflow tube would migrate towards the wall. In upflow conditions the opposite occurred, and the particles migrated towards the tube axis. Lipatov et al. [89] experimentally validated the effects of Saffman force using ducts in a wind tunnel. Ducts ranged from 3 to $10 \mathrm{~mm}$ in diameter and 10 to $25 \mathrm{~cm}$ in length. Monodisperse Lycopodium spores with a radius of $16 \mu \mathrm{m}$ were used as the aerosol particles. Flow velocities ranged from 0.4 to $1.5 \mathrm{~m} / \mathrm{s}$. The particle deposition coefficients for downflow and upflow $P_{d}$ and $P_{u}$, respectively, were calculated experimentally and analytically using Saffman force. It was found that $P_{d}$ ranged from 15 to $30 \%$ while $P_{u}$ was less than 3 . The large deviance of $P_{d}$ and $P_{u}$ is explained with Saffman force.

To model dust particles in the laminar region following a shock wave in coal mines, Wang and Osiptsov [62] and
Wang et al. [58] included both Stokes and Saffman forces. It was shown that Magnus force is not relevant in this situation because the particles' angular velocities were near the same order of magnitude as the velocity in the direction perpendicular to the wall. Saffman force was calculated with the correction factor used by Mei et al. [59] in Equation Set (26). Stokes force was calculated using (22). It was noticed that a lateral migration of particles from a wall caused localized accumulations away from the wall. A Lagrangian approach to determining velocities was used in $[58,62]$ with two-way coupling of the particles and the fluid under high particle concentrations in [58]. Hwang [90] used Saffman force in a similar situation with a weak shock wave in a dust deposit. It was determined that after the shock wave, a velocity gradient and subsequent force acting on the dust particles perpendicular to the velocity gradient were created.

Numerical calculations using a computational fluid dynamics (CFD) program, which takes into account Saffman force, have been studied by Kuan and Schwarz [61] and El-Batsh [91]. Kuan and Schwarz [61] studied coal dust of $40-80 \mu \mathrm{m}$ mean diameter in vertical ducts used for coalfired power plants. Particle tracking was accomplished using the Lagrangian approach. El-Batsh [91] used Saffman force to model near wall interaction of aerosol particles with a turbine cascade in turbulent flow. Barton [92] used Saffman force in a model which developed a fourth-order RungeKutta method to solve the equations of motion for flow of particles over a "backward-facing step." The model included Stokes drag force, gravity, virtual mass, pressure, and Basset force (history integral). It was determined that particles followed the streamlines for low Stokes number and overshot the streamlines for higher Stokes numbers where the effects of Saffman force increased as the particle Stokes number increased due to an increasing relative velocity (lag) of the particles.

There is literature which describes the modeling of aerosol particles in a nozzle (microcapillary) using variations of Stokes force and particle inertia without Saffman force by de la Mora and others [40, 41, 47, 84, 88]. Saffman force is used primarily along unbounded walls and long tubes or capillaries by Wang and Mei [58, 59, 62], for example. The inclusion of Saffman force on the focusing of aerosol particles through a nozzle may be necessary for a more complete model as we have described in [8, 68]; Stokes force, Saffman force, and particle inertia were required to describe the focusing of aerosol particles emanating from a microcapillary.

\section{Experimental Validation of Aerosol Physics}

The theoretical modeling of the fluid-particle interactions of aerosols is an invaluable tool in predicting the focusing of aerosol particles. The accuracy of the models and subsequent predictions must be verified by experimental observations before a complete understanding of the physics of aerosols, and ensuing improvement in A-DW techniques is realized. Much work is published on methods of quantifying aerosol focusing indirectly by measuring the width of deposits on a substrate. Rao et al. [80] and Mallina et al. [47], for example 


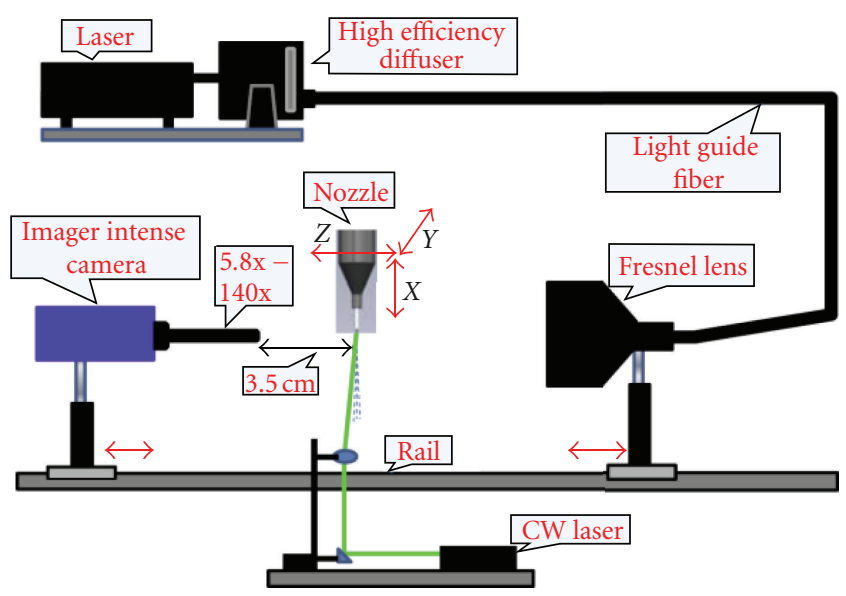

FIGURE 13: Schematic of shadowgraph system for the measurement of aerosol particles, from Mahmud et al. [86], Copyright 2010 ASME. Reprinted with permission.

used a greased substrate to capture aerosol particles and approximate the beam width. Fuerstenau et al. [72] and Akhatov et al. [68] directly measured the aerosol beam width by imaging the scattered light from aerosol particles exiting an orifice and nozzle, respectively. Much like the deposited line on greased plates, the images obtained from the scattered beam create a histogram of the aerosol particles at that given location, where information about individual particle trajectories and how focusing occurs for these particles are not directly known. Particle image velocimetry (PIV) using a scattered laser light sheet with seeded aerosol particles is commonly used to determine the trajectory of a fluid flow field at macroscale dimensions, but PIV is not designed for individual aerosol particle tracking and is extremely difficult to implement at the microscale.

We recently implemented a shadowgraph method to determine trajectories of individual particles focused by a nozzle [86]. A PIV system with shadowgraph option available from La Vision Inc. was used to measure the aerosol particles exiting a linearly converging nozzle. A schematic of the system is shown in Figure 13. Illumination is provided by a pair of Nd:YAG pulsed lasers, fed into a dye laser, liquid fiber guide, and Fresnel lens. The aerosol stream is placed between the camera and light source and produces a shadow on the camera. For alignment and comparison to previous results with scattered light, a CW laser is also incorporated into the system. This system is advantageous in that it is capable of measuring the particle location, velocity, and size simultaneously.

Results of these measurements are shown in Figures 14(a), 14(b), and 14(c), where (a) particle size distribution, (b) average, minimum, and maximum particle velocity versus distance from the nozzle exit, and (c) beam width from light scattering and number of particles from shadowgraph versus the radial position (focus) are displayed. In this case, the particle size distribution from an ultrasonic atomizer is around $2.5 \mu \mathrm{m}$ in diameter, well within the assumed range for modeling of 0.5 to $5 \mu \mathrm{m}$. Particle velocities are shown to increase up until about $1 \mathrm{~mm}$ away from the nozzle. These results are in agreement with the theoretical modeling, where focused particles increased velocity outside of the nozzle and later decreased. Finally, the beam width of the aerosol particles measured by the CW laser and by shadowgraph is very similar. Results of all these measurements show the validity of the shadowgraph method to characterize the aerosol stream exiting a nozzle for particle size, velocity, and distribution. Future results will allow additional refinement of fluid-particle forces giving a more accurate model for predicting aerosol focusing [86].

\section{Aerosol Direct-Write Applications}

A-DW technologies are still maturing, and the application of these to electronics has not been fully established. There are, however, abundant examples in literature of devices with one to all components being A-DW printed. The ability to print using a noncontact, rapid prototyping tool is especially beneficial in the development phase of technology where the time and costs associated with masks are the limiting factor. In addition, the noncontact high aspect-ratio characteristics possible for features printed with A-DW may prove useful in certain niche markets such as solar cells. All A-DW technologies are capable of printing straight traces which may be amenable for interconnects and vias in simple circuitry. Examples of applications of A-DW are quite prevalent, with advantages of using A-DW (Aerosol Jet specifically) described by King and Renn [87] as follows: firstly, reduced time for product development due to maskless approach; secondly, lower costs associated with mask setup for initial small production runs; thirdly, greater material utilization which reduces costs and is more environmentally friendly. They also describe one specific application for 3D interconnects where the large stand-off distance makes it possible to print traces over objects such as an alumina cube as illustrated in Figure 15.

MCS is capable of printing traces from solid aerosols of tin, aluminum, and copper onto various hard and flexible substrates. Formation of continuous lines depends upon both the substrate materials as well as the solid particles being deposited. Table 4 shows a list of the substrates with a $(+)$ or $(-)$ designating whether or not a particular solid metal aerosol gave a continuous line. Electrical properties were measured for copper traces prepared using a $100 \mu \mathrm{m}$ focusing nozzle, $400 \mathrm{ccm}$ carrier gas (aerosol) flow, $\sim 0.75 \mathrm{MPa}$ accelerator (sheath) gas pressure, $0.5 \mathrm{~mm}$ stand-off distance, and a $1 \mathrm{~mm} / \mathrm{s}$ translation speed (greater speeds possible). These traces were $\sim 50 \mu \mathrm{m}$ wide (Figure 16) and had a resistivity of $1.9 \mu \Omega-\mathrm{cm}$. In addition to metallic traces, the ability to fill vias from $75 \mu \mathrm{m}$ to $150 \mu \mathrm{m}$ in diameter with metals was demonstrated, creating the possibility of including trace deposition and via filling into one process.

Aerosol Jet was used to print conducting silver traces on plastic and printed circuit boards (PCBs) for use in an all direct-written chemisensor for the detection of nerve gas [93]. In this design, a polymer/carbon black composite was spray coated over sets of interdigitated traces on a PCB board. The silver traces were $20-50 \mu \mathrm{m}$ wide and $8-10 \mu \mathrm{m}$ thick and had a conductivity of $4-12 \mu \Omega$-cm after sintering 

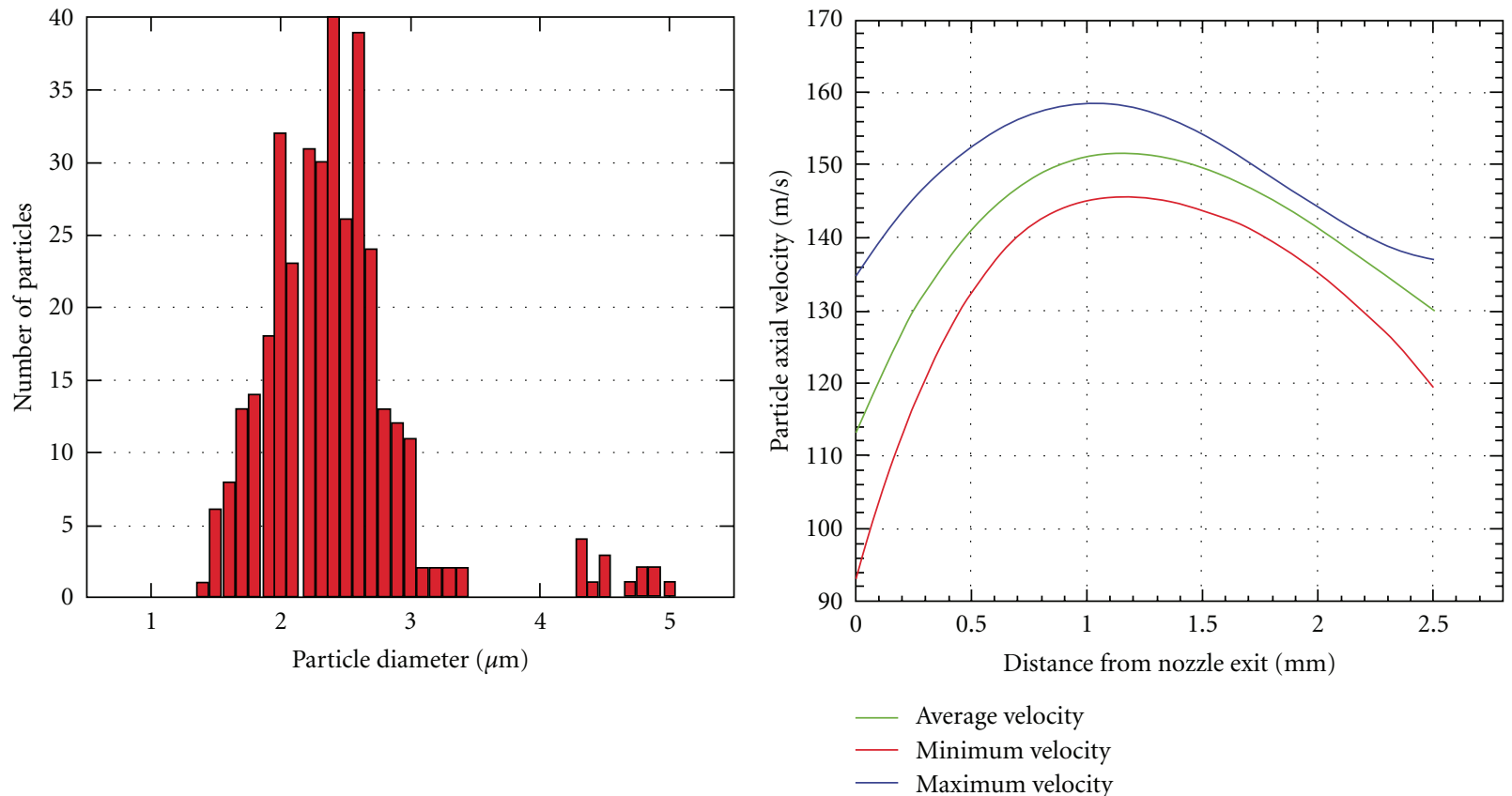

(a)

(b)

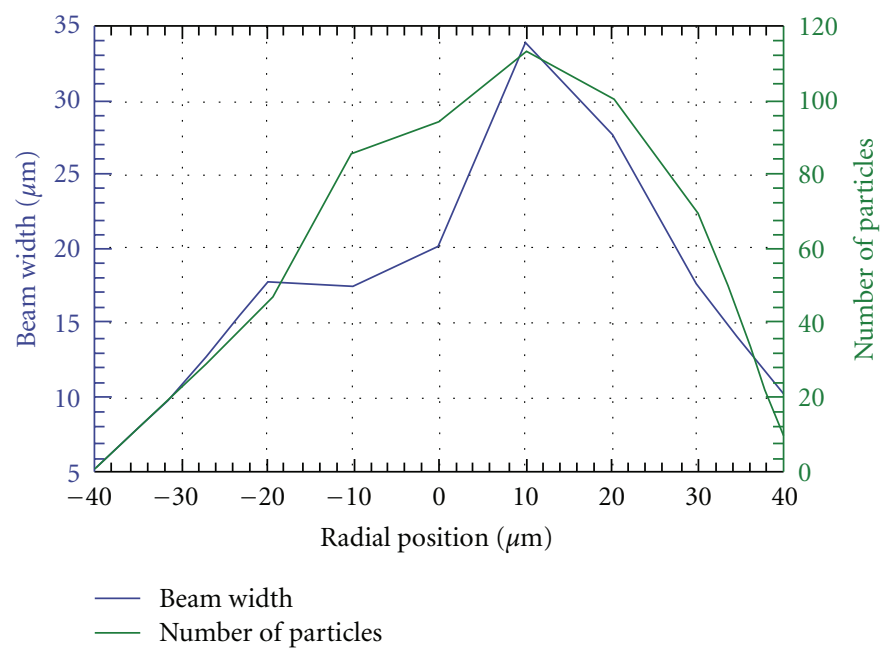

(c)

FIGURE 14: Shadowgraph results showing (a) histogram of particle size, (b) particle velocity versus distance from the nozzle exit, and (c) CW laser beamwidth and number of particles from shadowgraphy versus radial position (focus), from Mahmud et al. [86], Copyright 2010 ASME. Reprinted with permission.

at $200^{\circ} \mathrm{C}$. The composite consisted of a swelling copolymer such as ethylene/vinyl acetate and styrene/butadiene block copolymer with 5-20\% carbon black added for increased conductivity. The polymer would swell causing a change in resistivity. The chemisensors can be seen in Figure 17. The sensors were tested with a nerve gas simulant dimethylethyl phosphonate (DMMP). Results of the test conclude that the sensors do indeed work as intended, are reliable, and prove the viability of direct-written traces for gas chemisensors.

Other applications of Aerosol Jet include a technique developed by Marinov et al. [93] who developed what they term Enhanced $M^{3} \mathrm{D}$. This process has two steps; first a trench is laser machined into the substrate; second, a metal ink is direct-written into the trench. This technique may be beneficial for applications especially sensitive to overspray inherent in Aerosol Jet such as for radio frequency identification (RFID) tags because the trench defines the shape of the trace thereby decreasing edge effects and overspray which can be deleterious for high frequency transmission. Silver coplanar waveguides with and without the laser machined trench were prepared to test the improvement in the enhanced approach. Results of the test were promising with dc resistivity decreasing from 9.2 to $4.3 \mu \Omega-\mathrm{cm}$ and $\mathrm{AC}$ losses at $6 \mathrm{GHz}$ decreasing from $0.33 \mathrm{~dB} / \mathrm{mm}$ to $0.02 \mathrm{~dB} / \mathrm{mm}$ 


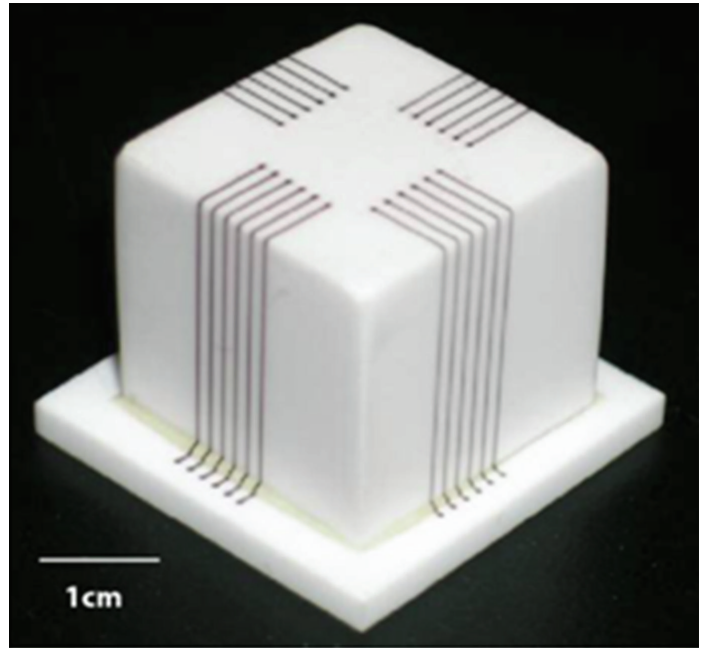

Figure 15: Aerosol Jet printed Ag traces, $150 \mu \mathrm{m}$ wide, on an alumina cube, from King and Renn [87], Copyright 2009 Optomec. Reprinted with permission.

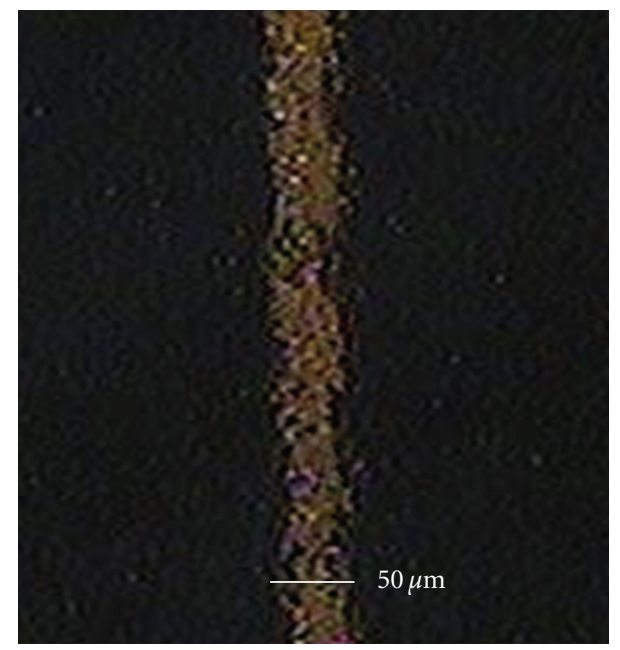

FIGURE 16: Image of MCS printed $50 \mu \mathrm{m}$ wide copper line on glass, from Bhattacharya et al. [11], Copyright 2012 ASME. Reprinted with permission.

for the waveguide without and with a laser machined trench. These results show that this two-step technique produces results typical to commercial devices where a loss in the range of 0.005 to $0.03 \mathrm{~dB} / \mathrm{mm}$ is common. Enhanced $\mathrm{M}^{3} \mathrm{D}$ is more expensive due to the two-step process, but considering a more than one decade improvement in losses, it may still be viable.

Maiwald et al. [94] reported the creation of strain gauges for nondestructive testing using Aerosol Jet. The devices are a multilayer structure utilizing a printed polymer isolation layer, $2 \mu \mathrm{m}$ thick, below a silver Aerosol Jet printed strain gauge, with $1-3 \mu \mathrm{m}$ thick traces, and printed encapsulation. The device on an aluminum surface is shown in Figure 18, where the total size of the sensor is only approximately $7 \mathrm{~mm}$ $\times 3 \mathrm{~mm}$. The silver nanoparticle ink used was procured from
TABLE 4: MCS material-substrate compatibility, from Bhattacharya et al. [11], Copyright 2012 ASME. Reprinted with permission.

\begin{tabular}{lccc}
\hline Substrate & Tin & Aluminum & Copper \\
\hline Glass & + & + & + \\
Silicon & + & + & + \\
BT $^{1}$ & + & + & - \\
PEEK $^{2}$ & - & + & + \\
Kapton & + & + & - \\
Teflon & - & + & + \\
PES $^{3}$ & - & + & + \\
LCP $^{4}$ & - & + & + \\
Teslin & - & - & + \\
FR4 & 5 & + & - \\
Mylar & - & + & + \\
\hline
\end{tabular}

${ }^{1}$ Fiberglass-reinforced Bismaleimide Triazine Epoxy.

${ }^{2}$ Polyether ether ketone.

${ }^{3}$ Polyethersulfone.

${ }^{4}$ Liquid crystal polymer.

${ }^{5}$ Glass-reinforced epoxy laminate.

Advanced Nano Products Inc. and produced metallic traces with up to $70 \%$ bulk conductivity at a sintering temperature of $350^{\circ} \mathrm{C}$. Experimental results show that the strain gauges work as expected, with a reliable sensor signal after repeated cycling. Aerosol Jet is beneficial in that it offers the ability to rapidly print strain gauges in arbitrary locations in a small form factor.

A-DW systems Aerosol Jet and CAB-DW along with MAPLE-DW were used to print silver nanoparticle-based RFID antennas on Kapton film at NDSU [95]. The goal of the research was to determine whether direct-write approaches were amenable to RFID applications. The antennas designed were based on "squiggle" patterns used by Alien Technology for their UHF $915 \mathrm{MHz}$ band tags. Each antenna which had different surface morphologies greatly depended on the type of A-DW tool used. Figure 19 displays each antenna, along with a detailed image of the surfaces, and edges where (a) is the Copper etched antenna, (b) is the CAB-DW printed antenna, (c) is the Aerosol Jet printed Antenna, and (d) is the MAPLE-DW printed antenna. After the printed traces were thermally postprocessed, RFID chips were attached, and the maximum read distance of the printed antenna RFID tags and commercially available copper-etched tags were measured. It was found that even though the thicknesses of the direct-written antennas were much less than $1 \mu \mathrm{m}$, as compared to $4 \mu \mathrm{m}$ for the copper etched tag, similar read distances were obtained. The results of this test are convincing evidence for the viability of using A-DW for the rapid prototyping of RFID antennas. The use of these techniques may assist RFID engineers with the development of new and improved antenna designs capable of increased read range.

Folgar et al. [101] produced multilayer structures using ceramic-based inks printed with Aerosol Jet to form capacitors. 3D structures were formed through the use of a combination of Aerosol Jet and selective laser sintering (SLS). Their work is additional evidence in the ability to use A-DW 


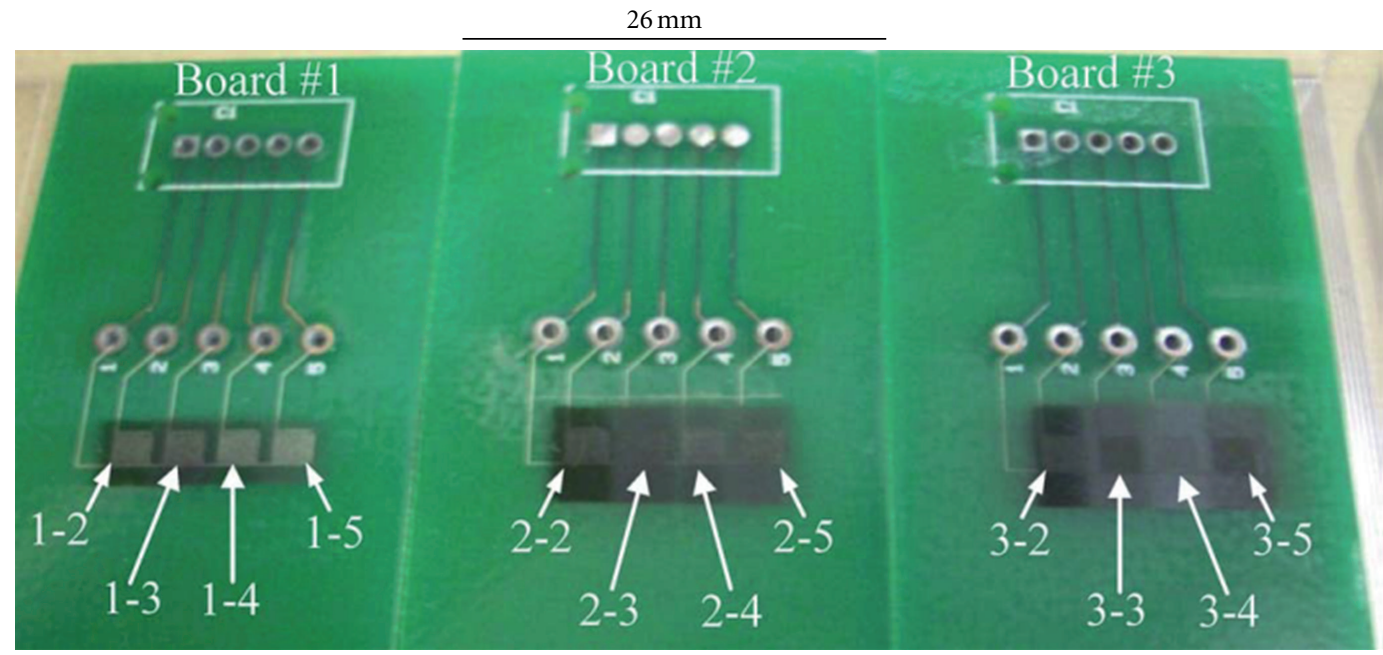

FIGURE 17: Optical micrograph of all-direct-written chemisensors for the detection of nerve gas, reprinted from Marinov et al. [93], Copyright 2007 IEEE.

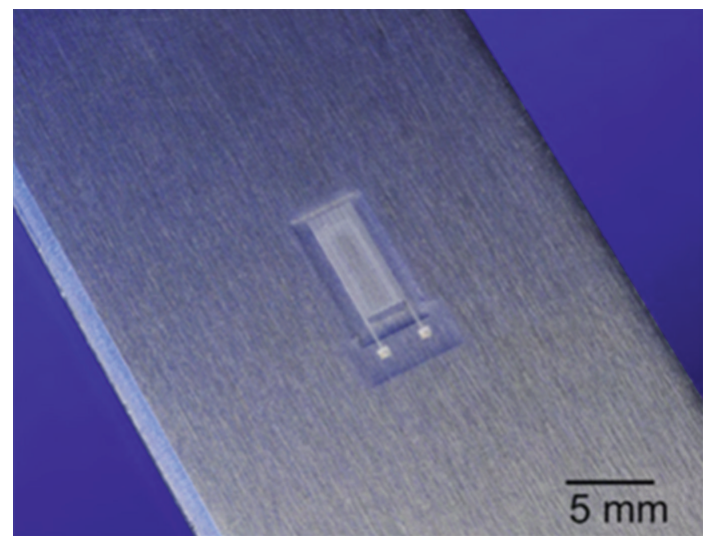

Figure 18: All Aerosol Jet printed strain gauge on aluminum substrate with polymer isolation and encapsulation, reprinted from Maiwald et al. [94], Copyright 2010, with permission from Elsevier.

systems for multilayer components. More complicated multilayer devices were built by $\mathrm{Ha}$ et al. [96] and Cho et al. [102] who used Aerosol Jet for TFTs with a printed CNT active layer. The source and drain were made via photolithography, while the rest of the device was printed. The active layer was printed using an aqueous dispersion of CNTs, the dielectric was a printed ion gel, and the gate was printed PEDOT:PSS. A diagram and image of the device are shown in Figures 20(a) and 20(b). This device is impressive in that the performance (i.e., mobility, switching speed) was improved from $200 \mu$ s to $50 \mu$ s when compared to other printed devices in literature even at a supply voltage below $3 \mathrm{~V}[96,103,104]$. In Ha's work, the TFT had a $50 \mu \mathrm{m} \times$ $400 \mu \mathrm{m}$ length and width, respectively. Jones et al. [97], Vaillancourt et al. [105], and King and Renn [87] each printed a similar CNT-based TFT using Aerosol Jet where features as fine as $10 \mu \mathrm{m}$ with channel lengths of $100 \mu \mathrm{m}$ are afforded [106]. An image of the TFT is shown in Figure 20(c). This TFT had the silver nanoparticle-based source, drain, and gate contact along with the CNT active layer, ion gel dielectric, and PEDOT gate produced by Aerosol Jet.

Silicon-based TFTs using CAB-DW printed source-drain contacts were produced at NDSU [107] where the active material $\left(\mathrm{Si}_{6} \mathrm{H}_{12}\right.$-based liquid silane ink) was spun onto silicon nitride coated silicon wafers [98]. Initial characterization of the TFT showed a field effect, but no performance characteristics (i.e., on/off ratio, mobility) were reported. Poly 3-hexylthiophene (P3HT) TFTs using CAB-DW printed source-drain electrodes were produced by Robinson et al. [98]. This TFT, as shown in Figure 21, consisted of an $\mathrm{n}^{++}$ doped silicon wafer, $300 \mathrm{~nm}$ silicon nitride gate dielectric, $15 \mu \mathrm{m}$ channel length silver nanoparticle-based source-drain electrodes, $50 \mathrm{~nm}$ spin-coated P3HT film using trichlorobenzene (TCB), and spin-coated poly (methyl methacrylate) (PMMA) in anisole (methoxybenzene). The TFT itself had a mobility of about $10^{-2} \mathrm{~cm}^{2} / \mathrm{V}$-s. This TFT illustrates the benefit of using CAB-DW's high-resolution $(5 \mu \mathrm{m})$ printing which is easily able to produce $15 \mu \mathrm{m}$ channel lengths.

The application of aerosol spray for solar cell metallization layers has been investigated by several groups for the printing of the top metallization layer. Benefits associated with A-DW are a consequence of the ability to print lines as thin as $5 \mu \mathrm{m}$ which affords a reduction in shadowing, series resistance, and production costs. Due to the noncontact approach utilized with aerosol spray, thinner wafers (i.e., $100 \mu \mathrm{m})$ can be used without the breakage associated with contact print methods such as screen printing giving a higher number of solar cells per Si single crystal boule $[17,108]$. We printed silver-based traces as thin as $7 \mu \mathrm{m}$ on heterojunction with intrinsic thin layer (HIT) solar cells produced in collaboration with NREL. The HIT cells utilize an indium tin oxide ITO transparent conducting oxide (TCO) lateral transport layer, so no burn-through was required [17, 109]. Results of this work concluded that an improvement in solar cell efficiency is realized when approximately $5 \mu \mathrm{m}$ traces are used in place of $90 \mu \mathrm{m}$ traces with similar geometric shadowing. The high $\left(9.8 \mathrm{~m} \Omega-\mathrm{cm}^{2}\right)$ contact resistance at the ITO-Ag 


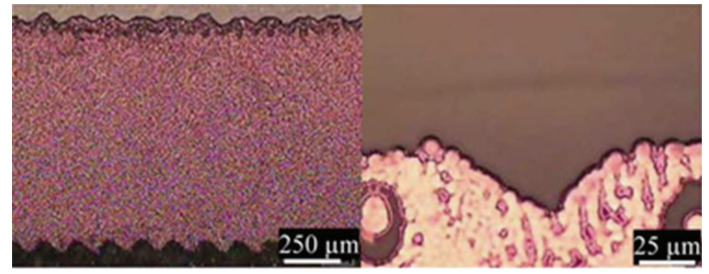

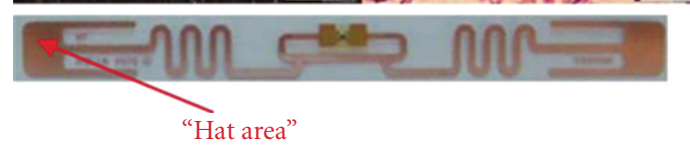

(a)
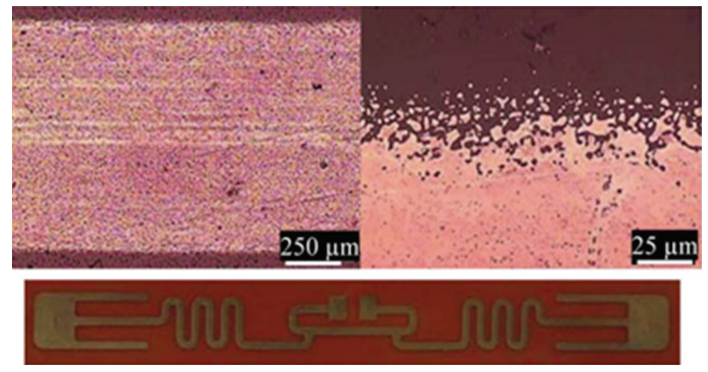

(c)

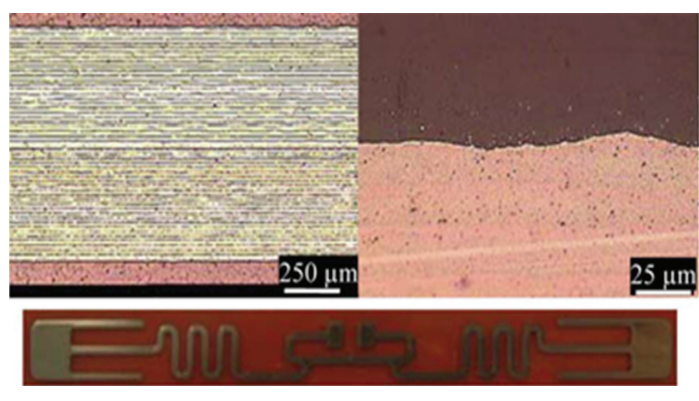

(b)

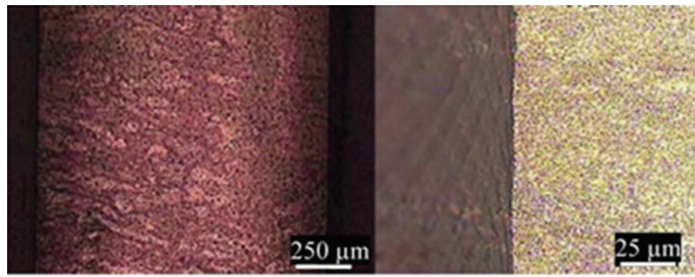

이달

(d)

FIGURE 19: Picture and micrographs of alien squiggle antennas made with (a) copper etching, (b) CAB-DW, (c) Aerosol Jet, and (d) MAPLEDW, reprinted from Hoey et al. [95], Copyright 2009 IEEE.
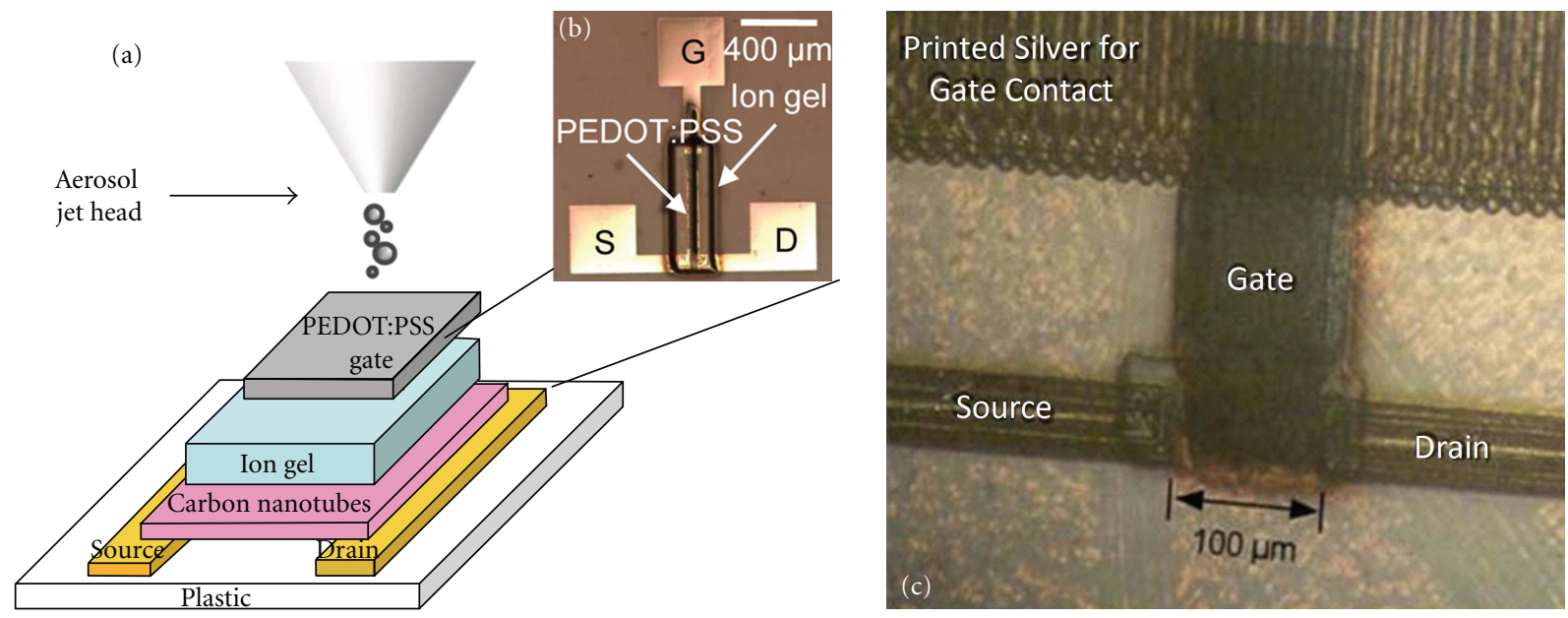

FIGURE 20: (a) Schematic representation of an Aerosol Jet printed CNT-based TFT. Source and drain were lithographically patterned while active (CNT), dielectric (ion gel), and gate (PEDOT:PSS) were made with Aerosol Jet. (b) Image of patterned TFT [96]. Copyright 2010 American Chemical Society. (c) Image of CNT based TFT with silver contacts produced by Aerosol Jet, spin-coated CNT film, ion gel dielectric, and PEDOT:PSS gate, reprinted from King and Renn, and Jones et al. [87, 97]. Copyright 2010, with permission from Optomec and Elsevier, respectively.

interface, which results in an increased series resistance in the cell, could possibly skew the comparison of results. Recent results using Ag nanoparticle inks show a contact resistance of $0.015 \mathrm{~m} \Omega-\mathrm{cm}^{2}$ and bulk resistivity of 3.5 to $4 \times$ bulk silver [110]. van Hest et al. $[108,111]$ utilized metal burnthrough inks designed for the $\mathrm{Si}_{3} \mathrm{~N}_{4}$ antireflection coating (ARC) on solar cells. They printed metal inks, based on a combination of silver, nickel, and copper, under ambient and inert atmospheres with trace widths of approximately
$50 \mu \mathrm{m}$. In addition to metal inks, they are currently investigating silicon dopant containing conductive inks, laser sintering of Aerosol Jet printed traces, and printed interdigitated back contact (IBC) cells. If more information about conductive inks for solar cells is desired, a review of printed inorganic solar cells and the available inks for conductive traces containing metalorganic, nanoparticle, and glass frit for example is written by that same group at NREL (Habas et al.) [112]. 


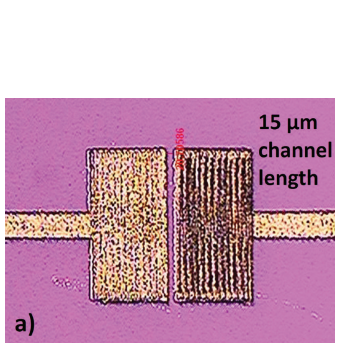

(a)

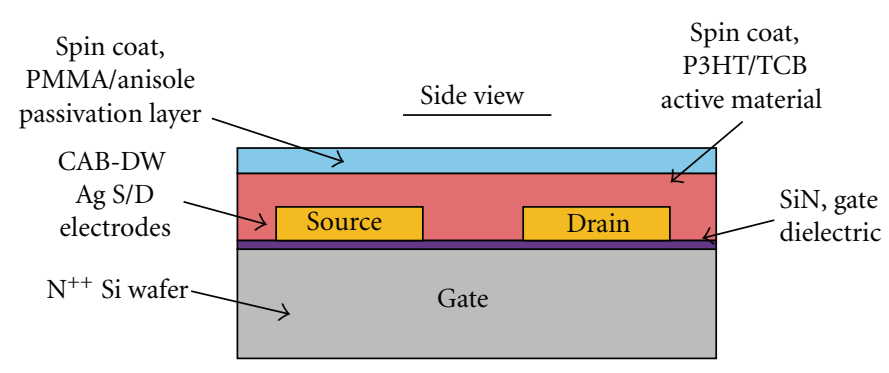

(b)

FIGURE 21: (a) Optical micrograph of Ag source and drain electrodes deposited by CAB-DW on $\mathrm{SiN}_{x}$-coated Si wafer with a channel length of $15 \mu \mathrm{m}$, (b) schematic of all-solution processed bottom-gate P3HT active TFT [98].

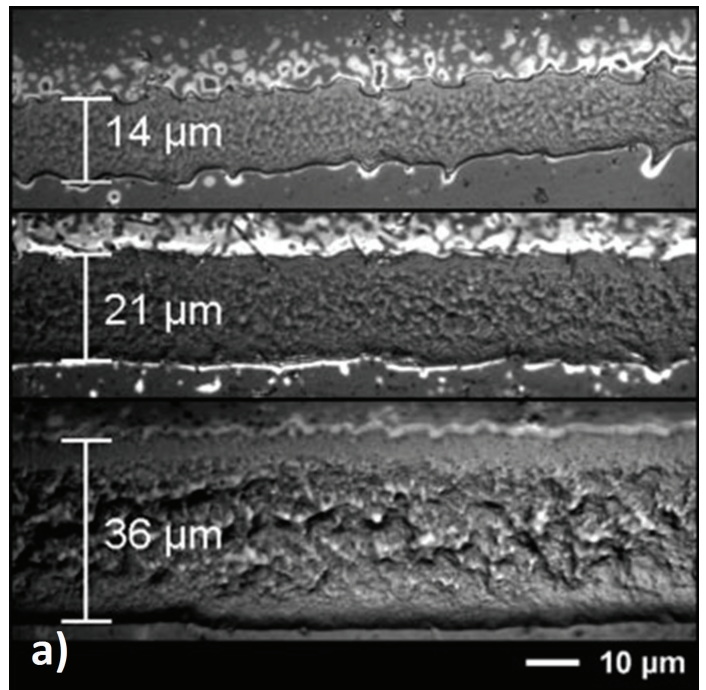

(a)

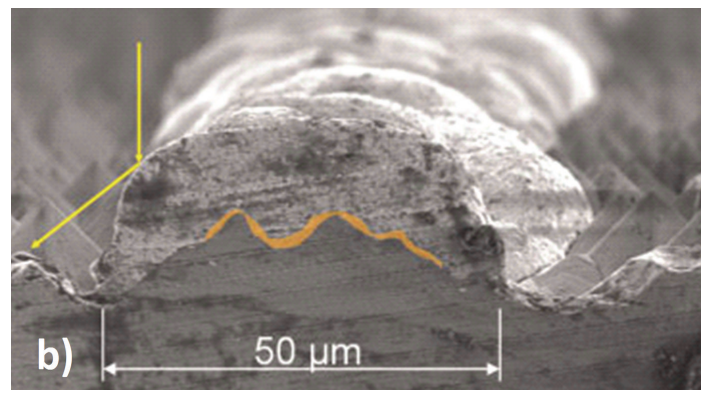

(b)

Figure 22: Aerosol Jet printed Ag traces for solar cells; (a) optical image prior to LIP, reprinted from Mette et al. [99], Copyright 2007, with permission from John Wiley \& Sons LTD. (b) SEM image of cross-section of Aerosol Jet printed trace with LIP. Aerosol Jet printed seed layer is highlighted in orange, reprinted from Horteis and Glunz [100], Copyright 2008, with permission from John Wiley \& Sons LTD.

Researchers at Fraunhofer ISE [99, 100, 113] devised a front metallization scheme in which the front side metallization layer is deposited with Aerosol Jet, cured, and followed with a light-induced plating (LIP) of silver. The LIP process preferentially electroplates silver onto the Aerosol Jet printed traces when the solar cell is under illumination due to the potential on the metal. A final line width of $50 \mu \mathrm{m}$ and height of $10 \mu \mathrm{m}$ can be achieved with a $25-30 \mu \mathrm{m}$ wide by $1 \mu \mathrm{m}$ high Aerosol Jet printed seed layer. This method reduced the series resistance loss normally resulting from the greater than bulk resistivity of printed silver traces by plating silver onto the contact thereby reducing the effective bulk resistivity [100]. Seed layer traces as thin as $14 \mu \mathrm{m}$ could be achieved with a metalorganic ink, but with poor edge definition as illustrated in Figure 22(a) [99]. An SEM image of the finished trace on a solar cell with the seed layer shown in orange can be seen in Figure 22(b) [100]; notice that the majority of the volume of the trace is plated silver. The procedure used by Fraunhofer greatly reduces the complexity of solar cell manufacturing as compared to a photolithographically defined metallization layer and may see commercial application. An improvement to the Aerosol Jet with LIP method was reported by Drew et al. [113] where laser chemical processing (LCP) was used to simultaneously form selective heavily doped emitters and burn through the $\mathrm{SiO}_{2}$ ARC layer before Aerosol Jet printing. Minimum contact resistance achieved with Aerosol Jet was $0.99 \mathrm{~m} \Omega-\mathrm{cm}^{2}$, much greater than that achieved with evaporated $\mathrm{Ti} / \mathrm{Pd} / \mathrm{Ag}$ contacts $\left(\sim 0.15 \mathrm{~m} \Omega-\mathrm{cm}^{2}\right)$, but low enough to be used for 1-sun illumination [113]. Without LCP treatment, minimum contact resistance was $2 \mathrm{~m} \Omega-\mathrm{cm}^{2}$ [100]. This method is another example of the innovations possible with A-DW technologies combined with other techniques.

\section{Conclusions}

Aerosol direct-write is a relatively new class of technologies rapidly becoming available for commercial use in electronic applications where a noncontact, high-resolution, and $3 \mathrm{D}$ capable tool is required. Aerosol Jet is the leading commercial technology available for A-DW, with CABDW, MCS, and aerosol lens focusing still in development stages. These devices all rely on aerodynamic focusing to create controllably fine deposits. The understanding of the physics of the fluid-particle interactions enables developers of A-DW technologies to further improve these devices reducing overspray, improving resolution, and decreasing tool downtime. Recent advancements in aerosol visualization and measurement using shadowgraphy and other techniques 
have led to an improved understanding of aerosol focusing as pertaining to A-DW technologies.

The coupling of A-DW technology to electronics leads to several advantages over traditional techniques including reduced costs, reduced time to startup, and improved feature resolution. A-DW has been shown capable of printing features for electronic devices such as TFTs and solar cells. Newer technologies such as MCS are not used in many applications, but have been shown capable of printing without postprocessing, a feature which could reduce production costs. The overall development of A-DW technologies may lead to a more widespread use for microelectronics applications especially those where rapid prototyping is employed.

\section{Acknowledgments}

The authors would like to thank Dr. Orven Swenson, Dr. Zakaria Mahmud, Dr. Greg McCarthy, Dr. Larry Pederson, Aaron Reinholz, Sourin Bhattacharya, Mike Robinson, Jacob Fink, Rob Sailer, Jason Daugs, and Drew Thompson for collaboration, helpful discussions, and support. This work was based on research sponsored by the Defense Microelectronics Activity (DMEA) under Agreement no. H9400311-2-1102. The views and conclusions contained herein are those of the authors and should not be interpreted as necessarily representing the official policies or endorsements, either expressed or implied, of the Defense Microelectronics Activity.

\section{References}

[1] A. D. Halvorsen, P. Vaidya, M. Robinson, and D. L. Schulz, "Transforming a laser micromachiner into a direct-write tool for electronic materials," Journal of MicroElectronics and Electronic Packaging, vol. 5, pp. 116-121, 2008.

[2] K. K. B. Hon, L. Li, and I. M. Hutchings, "Direct writing technology—advances and developments," CIRP Annals, vol. 57, no. 2, pp. 601-620, 2008.

[3] W. Liu and J. N. DuPont, "Fabrication of functionally graded TiC/Ti composites by laser engineered net shaping," Scripta Materialia, vol. 48, no. 9, pp. 1337-1342, 2003.

[4] M. J. Renn, G. Marquez, B. King, M. Essien, and W. Miller, "Flow-and laser-guided direct write of electronic and biological components," in Direct-Write Technologies For Rapid Prototyping Applications, A. Pique and D. B. Chrisey, Eds., pp. 475-492, Academic Press, San Diego, Calif, USA, 2002.

[5] Mesoscribe Technologies, http://www.mesoscribe.com/.

[6] D. B. Chrisey, A. Pique, R. Modi, H. D. Wu, R. C. Y. Auyeung, and H. D. Young, "Direct writing of conformal mesoscopic electronic devices by MAPLE DW," Applied Surface Science, vol. 168, no. 1-4, pp. 345-352, 2000.

[7] A. Lutfurakhmanov, G. K. Loken, D. L. Schulz, and I. S. Akhatov, "Capillary-based liquid microdroplet deposition," Applied Physics Letters, vol. 97, no. 12, Article ID 124107, 3 pages, 2010.

[8] I. S. Akhatov, J. M. Hoey, O. F. Swenson, and D. L. Schulz, "Aerosol flow through a long micro-capillary: collimated aerosol beam," Microfluidics and Nanofluidics, vol. 5, no. 2, pp. 215-224, 2008.

[9] J. M. Hoey, I. S. Akhatov, O. F. Swenson, and D. L. Schulz, "Convergent-divergent-convergent nozzle focusing of aerosol particles for micron-scale direct writing," 2009/0053507, 2009.

[10] R. A. Sailer and J. M. Hoey, "Micro cold spray direct write technology for printed micro electronics applications," US Patent 61/591, 365, 2012.

[11] S. Bhattacharya, A. Lutfurakhmanov, J. M. Hoey, O. F. Swenson, and R. A. Sailer, Micro Cold Spray Direct Write Process, ASME International Mechanical Engineering Congress and Exposition, Houston, Tex, USA, 2012.

[12] L. Qi, Aerosol printing of colloidal nanocrystals by aerodynamic focusing [Ph.D. thesis], Materials Science and Engineering, University of Minnesota, Minneapolis, Minn, USA, 2010.

[13] L. Qi, P. H. McMurry, D. J. Norris, and S. L. Girshick, "Impact dynamics of colloidal quantum dot solids," Langmuir, vol. 27, no. 20, pp. 12677-12683, 2011.

[14] S. L. Girshick, "Aerosol processing for nanomanufacturing," Journal of Nanoparticle Research, vol. 10, no. 6, pp. 935-945, 2008.

[15] L. Qi, P. H. McMurry, D. J. Norris, and S. L. Girshick, "Micropattern deposition of colloidal semiconductor nanocrystals by aerodynamic focusing," Aerosol Science and Technology, vol. 44, no. 1, pp. 55-60, 2010.

[16] M. J. Renn, “Direct Write System,” USA Patent 7108894 B2, 2006.

[17] J. Hoey, D. Thompson, M. Robinson et al., "CAB-DW for $5 \mu \mathrm{m}$ trace-width deposition of solar cell metallization topcontacts," in Proceedings of the 34th IEEE Photovoltaic Specialists Conference (PVSC '09), Philadelphia, Pa, USA, June 2009.

[18] D. L. Schulz, J. M. Hoey, D. Thompson et al., "Collimated aerosol beam deposition: sub-5- $\mu \mathrm{m}$ resolution of printed actives and passives," IEEE Transactions on Advanced Packaging, vol. 33, no. 2, pp. 421-427, 2010.

[19] A. Papyrin, V. Kosarev, S. Klinkov, A. Alkhimov, and F. Fomin, Cold Spray Technology, Elsevier Science, 2007.

[20] R. G. Maev and V. Leshchynsky, Introduction to Low Pressure Gas Dynamic Spray: Physics \& Technology, Wiley-VCH, Weinheim, Germany, 2008.

[21] A. Papyrin, "Cold spray technology," Advanced Materials and Processes, vol. 159, no. 9, pp. 49-51, 2001.

[22] Sono-Tek Homepage, http://www.sono-tek.com/.

[23] "Sonaer Ultrasonics Homepage," 2011, http://www.sonozap .com/.

[24] S. C. Tsai, Y. L. Song, C. S. Tsai, Y. F. Chou, and C. H. Cheng, "Ultrasonic atomization using $\mathrm{MHz}$ silicon-based multipleFourier horn nozzles," Applied Physics Letters, vol. 88, no. 1, Article ID 014102, 3 pages, 2006.

[25] J. Ju, Y. Yamagata, H. Ohmori, and T. Higuchi, "High-frequency surface acoustic wave atomizer," Sensors and Actuators A, vol. 145-146, no. 1-2, pp. 437-441, 2008.

[26] A. Qi, L. Y. Yeo, and J. R. Friend, "Interfacial destabilization and atomization driven by surface acoustic waves," Physics of Fluids, vol. 20, no. 7, Article ID 074103, 14 pages, 2008.

[27] J. Friend and L. Y. Yeo, "Microscale acoustofluidics: microfluidics driven via acoustics and ultrasonics," Reviews of Modern Physics, vol. 83, no. 2, pp. 647-704, 2011.

[28] N. S. Kim and K. N. Han, "Future direction of direct writing," Journal of Applied Physics, vol. 108, no. 10, Article ID 102801, 2010.

[29] “ANSYS CFX-Solver Theory Guide," 2011.

[30] I. S. Akhatov, J. M. Hoey, D. Thompson et al., "Aerosol flow through a micro-capillary," in Proceedings of the ASME 2nd Micro/Nanoscale Heat and Mass Transfer International Conference (MNHMT'09), pp. 223-232, December 2009. 
[31] C. T. Crowe, M. Sommerfeld, and Y. Tsuji, Multiphase Flows with Droplets and Particles, CRC Press, 1998.

[32] I. Kim, S. Elghobashi, and W. A. Sirignano, "On the equation for spherical-particle motion: effect of Reynolds and acceleration numbers," The Journal of Fluid Mechanics, vol. 367, pp. 221-253, 1998.

[33] J. S. Marshall, "Discrete-element modeling of particulate aerosol flows," Journal of Computational Physics, vol. 228, no. 5, pp. 1541-1561, 2009.

[34] F. Odar and W. S. Hamilton, "Forces on a sphere accelerating in a viscous fluid," The Journal of Fluid Mechanics, vol. 18, pp. 302-314, 1964.

[35] J. Ran, L. Zhang, Q. Tang, and M. Xin, "Numerical simulation of the particle motion characteristics in boundary layer of gas-solid rotary flow," Journal of Fluids Engineering, Transactions of the ASME, vol. 128, no. 3, pp. 596-601, 2006.

[36] P. G. Saffman, "Lift on a small sphere in a slow shear flow," The Journal of Fluid Mechanics, vol. 22, pp. 385-400, 1965.

[37] R. I. Nigmatulin, Dynamics of Multiphase Media, vol. 1-2, Hemisphere, New York, NY, USA, 1991.

[38] P. A. Baron, P. Kulkarni, and K. Willeke, Aerosol Measurement: Principles, Techniques, and Applications, Wiley, 2011.

[39] G. G. Stokes, "On the effect of the internal friction of fluids on the motion of pendulums," Transactions of the Cambridge Philosophical Society, vol. 9, pp. 8-108, 1851.

[40] J. Fernandez de la Mora and P. Riesco-Chueca, "Aerodynamic focusing of particles in a carrier gas," The Journal of Fluid Mechanics, vol. 195, pp. 1-21, 1988.

[41] Z. Li and H. Wang, "Drag force, diffusion coefficient, and electric mobility of small particles. I. Theory applicable to the free-molecule regime," Physical Review E, vol. 68, no. 6, Article ID 061206, 9 pages, 2003.

[42] R. A. Millikan, "Coefficients of slip in gases and the law of reflection of molecules from the surfaces of solids and liquids," Physical Review, vol. 21, no. 3, pp. 217-238, 1923.

[43] R. W. Johnson, The Handbook of Fluid Dynamics, CRC Press, Washington, DC, USA, 1998.

[44] E. Cunningham, "On the velocity of steady fall of spherical particles through fluid medium," Proceedings of the Royal Society of London Series A, vol. 83, pp. 357-365, 1910.

[45] D. J. Carlson and R. F. Hoglund, "Particle drag and heat transfer in rocket nozzles," AIAA, vol. 2, pp. 1980-1984, 1964.

[46] M. Knudsen and S. Weber, "Luftwiderstand gegen die langsame bewegung kleiner kugeln," Annals of Physics, vol. 36, pp. 981-994, 1911.

[47] R. V. Mallina, A. S. Wexler, and M. V. Johnston, "High-speed particle beam generation: simple focusing mechanisms," Journal of Aerosol Science, vol. 30, no. 6, pp. 719-738, 1999.

[48] M. D. Allen and O. G. Raabe, "Re-evaluation of millikan's oil drop data for the motion of small particles in air," Journal of Aerosol Science, vol. 13, no. 6, pp. 537-547, 1982.

[49] I. Langmuir, Filtration of Aerosols and Development of Filter Materials, Office of Scientific Research and Development, 1942.

[50] C. N. Davies, "Definitive equations for the fluid resistance of spheres," Proceedings of the Physical Society, vol. 57, no. 4, article 301, pp. 259-270, 1945.

[51] W. DeMarcus and J. W. Thomas, Theory of a Diffusion Battery, Oak Ridge National Laboratory, 1952.

[52] A. Reif, "Aerosols: physical properties, instrumentation and techniques," in Aviation Medicine Selected Reviews, C. S. White, W. R. Lovelace II, and F. G. Hirsch, Eds., Pergamon Press, Oxford, UK, 1958.
[53] N. A. Fuchs, The Mechanics of Aerosols, Pergamon Press, Oxford, UK, 1964.

[54] B. Dahneke, J. Hoover, and Y. S. Cheng, "Similarity theory for aerosol beams," Journal of Colloid And Interface Science, vol. 87, no. 1, pp. 167-179, 1982.

[55] R. L. Buckley and S. K. Loyalka, "Cunningham correction factor and accommodation coefficient: interpretation of Millikan's data," Journal of Aerosol Science, vol. 20, no. 3, pp. 347-349, 1989.

[56] R. Clift, J. R. Grace, and M. E. Weber, Bubbles, Drops, and Particles, Dover, Mineola, NY, USA, 2005.

[57] L. Schiller and A. Nauman, "A drag coefficient correction," V.D.I. Zeitung, vol. 77, pp. 318-320, 1935.

[58] B. Wang, Y. Xiong, and A. N. Osiptsov, "Two-way coupling model for shock-induced laminar boundary-layer flows of a dusty gas," Acta Mechanica Sinica/Lixue Xuebao, vol. 21, no. 6, pp. 557-563, 2005.

[59] R. Mei, "An approximate expression for the shear lift force on a spherical particle at finite reynolds number," International Journal of Multiphase Flow, vol. 18, no. 1, pp. 145-147, 1992.

[60] Q. Wang, K. D. Squires, and O. Simonin, "Large eddy simulation of turbulent gas-solid flows in a vertical channel and evaluation of second-order models," International Journal of Heat and Fluid Flow, vol. 19, no. 5, pp. 505-511, 1998.

[61] B. Kuan and M. P. Schwarz, "Numerical prediction of dilute particulate flow in horizontal and vertical ducts," in Proceedings of the 3rd International Conference on CFD in the Minerals and Process Industries, pp. 10-12, Melbourne, Australia, 2003.

[62] B. Y. Wang and A. N. Osiptsov, "Near-wall boundary layer behind a shock wave in a dusty gas," Fluid Dynamics, vol. 34, no. 4, pp. 505-515, 1999.

[63] J. L. M. Poiseuille, "Recherches sur les causes du mouvement du sang dans les vaisseaux capillaires," Annales Des Sciences Naturelles, vol. 5, p. 111, 1836.

[64] G. Segre and A. Silberberg, "Behavior of macroscopic rigid spheres in Poiseuille flow Part 2. Experimental results and interpretation," The Journal of Fluid Mechanics, vol. 14, pp. 136-157, 1962.

[65] J. P. Matas, J. F. Morris, and E. Guazzelli, "Lateral forces on a sphere," Oil and Gas Science and Technology, vol. 59, no. 1, pp. 59-70, 2004.

[66] D. R. Oliver, "Influence of particle rotation on radial migration in the poiseuille flow of suspensions," Nature, vol. 194, no. 4835, pp. 1269-1271, 1962.

[67] D. S. Dandy and H. A. Dwyer, "Sphere in shear flow at finite Reynolds number. Effect of shear on particle lift, drag, and heat transfer," The Journal of Fluid Mechanics, vol. 216, pp. 381-410, 1990.

[68] I. S. Akhatov, J. M. Hoey, O. F. Swenson, and D. L. Schulz, "Aerosol focusing in micro-capillaries: theory and experiment," Journal of Aerosol Science, vol. 39, no. 8, pp. 691-709, 2008.

[69] J. B. McLaughlin, "Inertial migration of a small sphere in linear shear flows," The Journal of Fluid Mechanics, vol. 224, pp. 261-274, 1991.

[70] G. N. Lipatov, T. I. Semenyuk, and S. A. Grinshpun, "Aerosol migration in laminar and transition flows," Journal of Aerosol Science, vol. 21, no. 1, pp. S93-S96, 1990.

[71] Y. S. Cheng and B. E. Dahneke, "Properties of continuum source particle beams: II. Beams generated in capillary expansions," Journal of Aerosol Science, vol. 10, no. 4, pp. 363368, 1979. 
[72] S. Fuerstenau, A. Gomez, and J. Fernández de la Mora, "Visualization of aerodynamically focused subsonic aerosol jets," Journal of Aerosol Science, vol. 25, no. 1, pp. 165-173, 1994.

[73] G. W. Israel and S. K. Friedlander, "High-speed beams of small particles," Journal of Colloid And Interface Science, vol. 24, no. 3, pp. 330-337, 1967.

[74] G. W. Israël and J. S. Whang, Dynamical Properties of Aerosol Beams: Institute for Fluid Dynamics and Applied Mathematics, University of Maryland, 1971.

[75] J. J. Stoffels, "A direct inlet for surface-ionization mass spectrometry of airborne particles," International Journal of Mass Spectrometry and Ion Physics, vol. 40, no. 2, pp. 223-234, 1981.

[76] M. P. Sinha, C. E. Giffin, D. D. Norris, T. J. Estes, V. L. Vilker, and S. K. Friedlander, "Particle analysis by mass spectrometry," Journal of Colloid And Interface Science, vol. 87, no. 1, pp. 140-153, 1982.

[77] T. J. Estes, V. L. Vilker, and S. K. Friedlander, "Characteristics of a capillary-generated particle beam," Journal of Colloid And Interface Science, vol. 93, no. 1, pp. 84-94, 1983.

[78] O. Kievit, J. C. M. Marijnissen, P. J. T. Verheijen, and B. Scarlett, "Some improvements on the particle beam generator," Journal of Aerosol Science, vol. 21, no. 1, pp. S685-S688, 1990.

[79] W. D. Reents Jr., S. W. Downey, A. B. Emerson et al., "Single particle characterization by time-of-flight mass spectrometry," Aerosol Science and Technology, vol. 23, no. 3, pp. 263270, 1995.

[80] N. P. Rao, J. Navascues, and J. Fernández de la Mora, "Aerodynamic focusing of particles in viscous jets," Journal of Aerosol Science, vol. 24, no. 7, pp. 879-892, 1993.

[81] P. Liu, P. J. Ziemann, D. B. Kittelson, and P. H. McMurry, "Generating particle beams of controlled dimensions and divergence: I. Theory of particle motion in aerodynamic lenses and nozzle expansions," Aerosol Science and Technology, vol. 22, no. 3, pp. 293-313, 1995.

[82] P. Liu, P. J. Ziemann, D. B. Kittelson, and P. H. McMurry, "Generating particle beams of controlled dimensions and divergence: II. Experimental evaluation of particle motion in aerodynamic lenses and nozzle expansions," Aerosol Science and Technology, vol. 22, no. 3, pp. 314-324, 1995.

[83] F. Di Fonzo, A. Gidwani, M. H. Fan et al., "Focused nanoparticle-beam deposition of patterned microstructures," Applied Physics Letters, vol. 77, no. 6, pp. 910-912, 2000.

[84] X. Wang and P. H. McMurry, "A design tool for aerodynamic lens systems," Aerosol Science and Technology, vol. 40, no. 5, pp. 320-334, 2006.

[85] X. Wang, A. Gidwani, S. L. Girshick, and P. H. McMurry, "Aerodynamic focusing of nanoparticles: II. Numerical simulation of particle motion through aerodynamic lenses," Aerosol Science and Technology, vol. 39, no. 7, pp. 624-636, 2005.

[86] Z. Mahmud, J. M. Hoey, A. Lutfurakhmanov et al., "Experimental characterization of aerosol flow through a microcapillary," in ASME Conference Proceedings, pp. 949-958, Montreal, Canada, 2010.

[87] B. King and M. Renn, "Aerosol Jet direct write printing for mil-aero electronic applications," http://www.optomec.com/, 2009.

[88] M. J. Renn, B. H. King, and M. Essien, "Maskless deposition technology targets passive embedded components," in Surface Mount Technology Association Pan Pacific Symposium, 2002.
[89] G. N. Lipatov, S. A. Grinshpun, and T. I. Semenyuk, "Properties of crosswise migration of particles in ducts and inner aerosol deposition," Journal of Aerosol Science, vol. 20, no. 8, pp. 935-938, 1989.

[90] C. C. Hwang, "Initial stages of the interaction of a shock wave with a dust deposit," International Journal of Multiphase Flow, vol. 12, no. 4, pp. 655-666, 1986.

[91] M. S. H. El-Batsh, "Modeling particle deposition on gas turbine blade surfaces".

[92] I. E. Barton, "Computation of particle tracks over a backward-facing step," Journal of Aerosol Science, vol. 26, no. 6, pp. 887-901, 1995.

[93] V. R. Marinov, Y. A. Atanasov, A. Khan et al., "Direct-write vapor sensors on FR4 plastic substrates," IEEE Sensors Journal, vol. 7, no. 6, pp. 937-944, 2007.

[94] M. Maiwald, C. Werner, V. Zoellmer, and M. Busse, "INKtelligent printed strain gauges," Sensors and Actuators, A, vol. 162, no. 2, pp. 198-201, 2010.

[95] J. M. Hoey, M. T. Reich, A. Halvorsen et al., "Rapid prototyping RFID antennas using direct-write," IEEE Transactions on Advanced Packaging, vol. 32, no. 4, pp. 809-815, 2009.

[96] M. Ha, Y. Xia, A. A. Green et al., "Printed, sub-3V digital circuits on plastic from aqueous carbon nanotube inks," ACS Nano, vol. 4, no. 8, pp. 4388-4395, 2010.

[97] C. S. Jones, X. Lu, M. Renn, M. Stroder, and W. S. Shih, "Aerosol-jet-printed, high-speed, flexible thin-film transistor made using single-walled carbon nanotube solution," Microelectronic Engineering, vol. 87, no. 3, pp. 434-437, 2010.

[98] M. Robinson, J. M. Hoey, D. Thompson et al., "Cyclohexasilane $\left(\mathrm{Si}_{6} \mathrm{H}_{12}\right)$ as a precursor to silicon based ring oscillators built with collimated aerosol beam-direct write (CAB-DW ${ }^{\mathrm{TM}}$ )," in MRS Spring Meeting, San Francisco, Calif, USA, 2009.

[99] A. Mette, P. L. Richter, M. Hörteis, and S. W. Glunz, "Metal aerosol jet printing for solar cell metallization," Progress in Photovoltaics, vol. 15, no. 7, pp. 621-627, 2007.

[100] M. Hörteis and S. W. Glunz, "Fine line printed silicon solar cells exceeding 20\% efficiency," Progress in Photovoltaics, vol. 16, no. 7, pp. 555-560, 2008.

[101] C. E. Folgar, C. Suchicital, and S. Priya, "Solution-based aerosol deposition process for synthesis of multilayer structures," Materials Letters, vol. 65, no. 9, pp. 1302-1307, 2011.

[102] J. H. Cho, J. Lee, Y. Xia et al., "Printable ion-gel gate dielectrics for low-voltage polymer thin-film transistors on plastic," Nature Materials, vol. 7, no. 11, pp. 900-906, 2008.

[103] L. Herlogsson, M. Cölle, S. Tierney, X. Crispin, and M. Berggren, "Low-voltage ring oscillators based on polyelectrolyte-gated polymer thin-film transistors," Advanced Materials, vol. 22, no. 1, pp. 72-76, 2010.

[104] Y. Xia, W. Zhang, M. Ha et al., "Printed sub-2 V Gel-electrolyte-gated polymer transistors and circuits," Advanced Functional Materials, vol. 20, no. 4, pp. 587-594, 2010.

[105] J. Vaillancourt, H. Zhang, P. Vasinajindakaw et al., "All inkjet-printed carbon nanotube thin-film transistor on a polyimide substrate with an ultrahigh operating frequency of over 5 GHz," Applied Physics Letters, vol. 93, no. 24, Article ID 243301, 3 pages, 2008.

[106] M. J. Renn, B. H. King, M. Essien, and L. J. Hunter, “Apparatuses and method for maskless mesoscale material deposition," US Patent 7045015, 2006.

[107] S. Han, X. Dai, P. Loy et al., "Printed silicon as diode and FET materials-Preliminary results," Journal of Non-Crystalline Solids, vol. 354, no. 19-25, pp. 2623-2626, 2008. 
[108] M. F. A. M. van Hest, "Direct write approaches for metallization," in Proceedings of the 2nd Workshop on Metallization of Crystalline Silicon Solar Cells, Cibstabcem, Germany, 2010.

[109] J. M. Hoey, J. Fink, M. Page, Q. Wang, I. S. Akhatov, and D. L. Schulz, "Collimated aerosol beam-direct write for solar cell metallization layer," in MRS Spring Meeting, p. C9.3, San Francisco, Calif, USA, 2010.

[110] J. Fink, J. M. Hoey, and D. L. Schulz, Fine Line Metallization of Silicon Solar Cells via Collimated Aerosol Beam Direct Write, ASME International Mechanical Engineering Congress and Exposition, Houston, Tex, USA, 2012.

[111] M. F. A. M. Van Hest, S. E. Habas, J. M. Underwood et al., "Direct write metallization for photovoltaic cells and scaling thereof," in Proceedings of the 35th IEEE Photovoltaic Specialists Conference (PVSC '10), pp. 3626-3628, Honolulu, Hawaii, USA, June 2010.

[112] S. E. Habas, H. A. S. Platt, M. F. A. M. Van Hest, and D. S. Ginley, "Low-cost inorganic solar cells: from ink to printed device," Chemical Reviews, vol. 110, no. 11, pp. 6571-6594, 2010.

[113] K. Drew, S. Hopman, M. Hörteis, S. W. Glunz, and F. Granek, "Combining laser chemical processing and aerosol jet printing: a laboratory scale feasibility study," Progress in Photovoltaics, vol. 19, no. 3, pp. 253-259, 2011. 

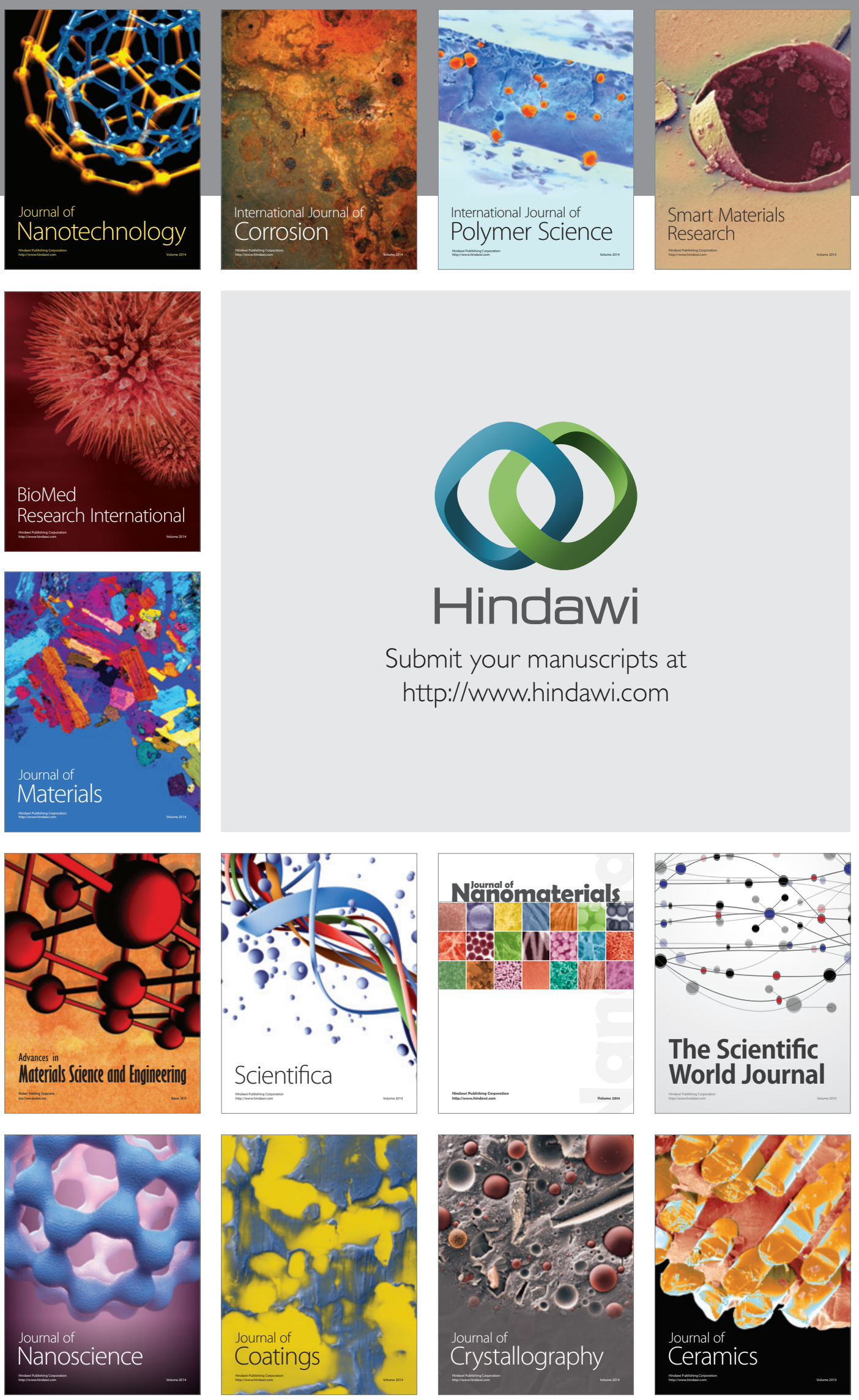

The Scientific World Journal

Submit your manuscripts at

http://www.hindawi.com

\section{World Journal}

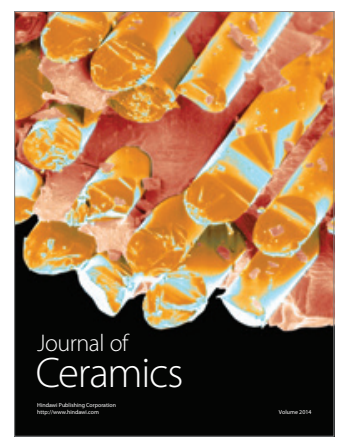

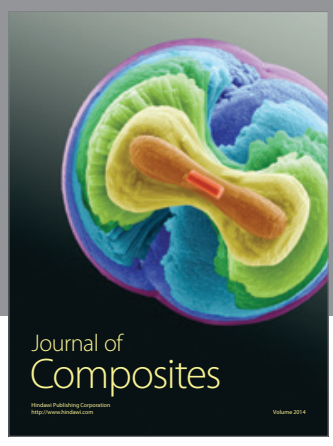
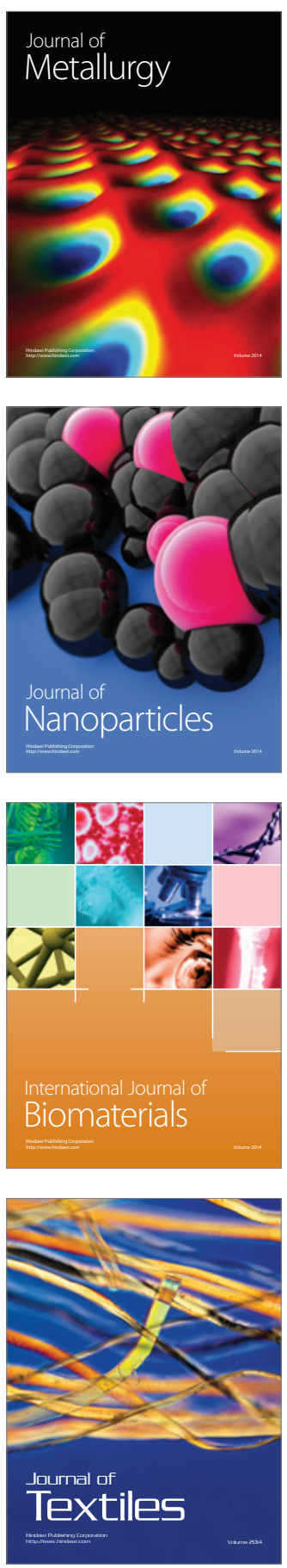